NBER WORKING PAPER SERIES

\title{
PARENTAL RESOURCES AND COLLEGE ATTENDANCE: EVIDENCE FROM LOTTERY WINS
}

\author{
George Bulman \\ Robert Fairlie \\ Sarena Goodman \\ Adam Isen \\ Working Paper 22679 \\ http://www.nber.org/papers/w22679
NATIONAL BUREAU OF ECONOMIC RESEARCH
1050 Massachusetts Avenue
Cambridge, MA 02138 \\ September 2016, Revised December 2020
}

We thank Scott Carrell, Oded Gurantz, Brad Hershbein, Nate Hilger, Lance Lochner, Paco Martorell, Benjamin Marx, Constantine Yannelis, Sarah Pack Reber, and seminar participants at the 2016 NBER Summer Institute Education Meeting, 2016 All California Labor Economics Conference, 2016 Annual Conference on Taxation, 2017 NBER Labor Studies Program Meeting, American University, Census Bureau, George Mason University, Stanford University, Urban Institute, University of Bonn, University of California at Santa Cruz, University of Illinois, and the University of Nevada at Reno for helpful comments and suggestions. Steve Ramos provided excellent research assistance. The views expressed herein are those of the authors and do not necessarily reflect the views of the Federal Reserve Board of Governors, National Bureau of Economic Research, or U.S. Department of the Treasury. All errors are our own.

NBER working papers are circulated for discussion and comment purposes. They have not been peer-reviewed or been subject to the review by the NBER Board of Directors that accompanies official NBER publications.

(C) 2016 by George Bulman, Robert Fairlie, Sarena Goodman, and Adam Isen. All rights reserved. Short sections of text, not to exceed two paragraphs, may be quoted without explicit permission provided that full credit, including $(\odot$ notice, is given to the source. 
Parental Resources and College Attendance: Evidence from Lottery Wins

George Bulman, Robert Fairlie, Sarena Goodman, and Adam Isen

NBER Working Paper No. 22679

September 2016, Revised December 2020

JEL No. I23

\section{ABSTRACT}

We examine U.S. children whose parents won the lottery to trace out the effect of financial resources on college attendance. The analysis leverages federal tax and financial aid records and substantial variation in win size and timing. While per-dollar effects are modest, the relationship is weakly concave, with a high upper bound for amounts greatly exceeding college costs. Effects are smaller among low-SES households, not sensitive to how early in adolescence the shock occurs, and not moderated by financial aid crowd-out. The results imply that households derive consumption value from college and household financial constraints alone do not inhibit attendance.

George Bulman

Department of Economics

University of California

1156 High Street

Santa Cruz, CA 95064

gbulman@ucsc.edu

Robert Fairlie

Department of Economics

Engineering 2 Building

University of California at Santa Cruz

Santa Cruz, CA 95064

and NBER

rfairlie@ucsc.edu
Sarena Goodman

Federal Reserve Board of Governors

20th \& Constitution Ave., NW

Washington, DC 20551

sarena.f.goodman@frb.gov

Adam Isen

Office of Tax Analysis

U.S. Department of the Treasury

1500 Pennsylvania Ave., NW

Washington, DC 20220

adam.isen@gmail.com 


\section{Introduction}

Given the large college wage premium and sizable gaps in college-going by socioeconomic background, understanding the relationship between household financial resources and college attendance is an important step to addressing inequality of opportunity. ${ }^{1}$ In theory, absent financial frictions, the decision to attend college should primarily reflect its net return. Indeed, a longstanding objective of higher education policy has been to abate or remove such frictions from this decision. ${ }^{2}$ Nonetheless, many households cite cost as a major factor in the decision not to attend (Federal Reserve Board, 2017), suggesting that resources may directly influence collegegoing. If so, households must still be financially constrained, must derive consumption value from college beyond its human capital benefits, or both.

Understanding this relationship requires overcoming the inherent identification challenge that resources and schooling decisions are correlated with children's ability levels, household preferences, and other factors. To address this challenge, a recent quasi-experimental literature exploits income differences generated by, for example, housing prices, job loss, oil revenue, and tax credits. ${ }^{3}$ The resulting estimates vary greatly in magnitude, ranging from less than 1 percentage point (p.p.) per $\$ 100,000$ to over 1 p.p. per $\$ 1,000$. This wide range likely reflects differences in the research designs — such as, the identifying assumptions, the affected populations, the size and salience of the changes in resources, the timing of the changes in children's lives, and offsetting effects of changes in financial aid eligibility — with the amount of weight attributable to any one factor difficult to ascertain. Altogether, despite considerable research in this area, there is a lack of consensus on 1) the degree to which household resources affect children's college-going and 2)

\footnotetext{
${ }^{1}$ Several studies, using distinct data sources, have identified sizable gaps in college attendance by socioeconomic background in the U.S. (e.g., Pallais and Turner, 2006; Bailey and Dynarski, 2011). Internationally, the average difference in the enrollment rate between children whose parents did or did not attend college is 38 percentage points for developed countries (OECD, 2017). College offers both pecuniary and non-pecuniary benefits (see Oreopoulos and Salvanes (2011) for an overview on non-pecuniary returns to higher education).

${ }^{2}$ See Hanushek, Leung, and Yilmaz (2014) and Page and Scott-Clayton (2016) for, respectively, a theoretical examination of and a review of the effectiveness of such policies in the U.S.

${ }^{3}$ Studies of the effect of resources on college attendance are described in the appendix and include Coelli (2011), Lovenheim (2011), Lovenheim and Reynolds (2013), Pan and Ost (2014), Hilger (2016), Bastian and Michelmore (2018), and Manoli and Turner (2018). Related literatures consider educational attainment (Shea, 2000; Akee et al., 2010; Bleakley and Ferrie, 2016; Loken, 2010), academic performance (Blau, 1999; Maurin, 2002; Ananat et al., 2011; Milligan and Stabile, 2011; Rege, Tella, and Votruba, 2011; Dahl and Lochner, 2012; Cesarini et al., 2016), and future economic outcomes (Bratberg, Nilsen, and Vaage, 2008; Oreopoulos, Page, and Stevens, 2008; Aizer et al., 2016).
} 
the extent to which these effects stem from easing financial constraints or consumption preferences.

This study pursues resolution to these questions by comprehensively examining the attendance effects of a clean resource shock within a single framework. Specifically, using federal tax records, we examine the college outcomes of children whose parents won a state lottery (ranging from \$600 to tens of millions of dollars) between 2000 and 2013. It is the first study to exploit variation among lottery winners to examine post-secondary attendance, a setting that offers several advantages relative to prior research in this area. ${ }^{4}$ Lottery wins are pure income shocks that do not load other factors that might confound interpretation, and the amount of the win is salient to the household. The wide range of lottery win amounts and the diversity of households affected allow us to paint a rich picture of the magnitude of resources needed to generate significant changes in college outcomes, to assess the degree of concavity and upper bound of these effects, and to document heterogeneity in the response by household socioeconomic status (SES) and children's ages at the time of the shock. Our national, third-party reported data also allow us to generate precise estimates and examine the representativeness of our population of study, the extent to which households spend or save lottery winnings, and potential mechanisms underlying the pattern of results.

The analysis uses the full set of tax filings associated with each lottery winning household, including enrollment records that colleges must file with the IRS, and a separate linkage to children's federal financial aid records. The empirical strategy leverages both the amount of the lottery win and, to address concerns that there may be unobserved differences between households that experience larger and smaller lottery wins, the timing of the win with respect to the child's age. Specifically, our strategy examines college attendance in the year of high school graduation. Then, estimates are derived by comparing differences in this outcome between children whose parents won large and small amounts before high school graduation to those between children whose parents won large and small amounts after high school graduation (i.e., too late for college attendance in the year of high school graduation to be affected). ${ }^{5}$ The resulting design is balanced across a rich set of household characteristics and is robust to falsification tests. We estimate both

\footnotetext{
${ }^{4}$ This study is also the first to examine any outcome using data on the population of U.S. lottery winners.

${ }^{5}$ Studies examining the effects of lotteries on labor supply, health, consumption, and cognitive development have taken various approaches to controlling for potential differences in household characteristics across lottery win amounts (e.g., see Imbens, Rubin, and Sacerdote, 2001; Lindahl, 2005; Hankins, Hoekstra, and Skiba, 2011; Kuhn et al., 2011; Powdthavee and Oswald, 2014; Apouey and Clark, 2015; Cesarini et al., 2016, 2017).
} 
a step function and a linear specification and also examine effects on enrollment in later years, time spent in college, and the types of colleges attended.

Our analysis reveals that small-to-moderate increases in resources, which should ease most immediate household financial constraints, have little effect on attendance. For example, we can rule out that lottery wins averaging \$50,000 (before taxes) increase enrollment by more than 0.4 percentage point (p.p.). However, our results do indicate a clear causal relationship between household resources and college attendance that is not highly concave. ${ }^{6}$ The per-dollar effect indicates a 0.6 p.p. increase in attendance per $\$ 100,000$ of additional household resources, which, while modest in comparison to many prior estimates, explains about one-third of the crosssectional relationship between household income over childhood and four-year college attendance in the tax data (Table 1). ${ }^{7}$ Further, the effect of resources achieves a high upper bound at amounts greatly exceeding the cost of college-averaging 10 p.p. for wins of $\$ 1,000,000$ or more. The pattern of results is robust to alternative specifications, adjusting win amounts for taxes, and expanding the definition of enrollment to also include the year after high school graduation. Enrollment increases are concentrated at four-year colleges, at those with higher expenditures on student amenities, and among children from neighborhoods with higher rates of college attendance. They are also evident in each of the four years after high school, consistent with a persistent effect. While moderate wins increase attendance at public colleges, the largest wins increase attendance at both public and private colleges.

Extended analyses produce several results that help shed additional light on the roles of financial constraints and consumption as mechanisms. First, we find that responsiveness is, if anything, smaller among households with lower earnings, less wealth, and with the highest propensity to be credit constrained. Second, the diversity of children's ages at which a win occurs allow us to examine the role of binding short-run constraints and constraints that limit complementary parental investment earlier in childhood. We find no evidence that resource shocks that occur earlier in a child's life have larger effects, either in general or for lower-SES households

\footnotetext{
${ }^{6}$ To examine concavity, we can observe households with the same baseline levels of income receiving vastly differentsized resource shocks and thus do not need to leverage the amount of households' prior resources or to assume that there is no treatment heterogeneity by socioeconomic background.

${ }^{7}$ Table 1 presents estimates of the OLS relationship between total household income during childhood and college attendance, over increasing ranges of average household income. Coefficients range from 1.2 to 1.7 p.p. per \$100,000 for four-year college attendance and 2.1 to 2.6 p.p. for any college attendance. We do not observe stronger correlations for income in the years immediately prior to high school graduation.
} 
in particular. ${ }^{8}$ Third, we develop a test that exploits the timing of wins with respect to key features of the federal financial aid formula - i.e., that wins that occur in the year prior to high school graduation are treated as income, which is heavily penalized in this formula, while wins that occur earlier than that year are treated as wealth, which is not - to account for potentially offsetting effects of changes in need-based financial assistance. This reveals that additional resources reduce need-based financial assistance but that crowd-out of such assistance does not significantly moderate the attendance estimates. Finally, the rich set of outcomes available in the tax data enable us to examine alternative margins of response, revealing that lower-SES households exhibit smaller reductions in earnings and smaller increases in savings, suggesting a higher marginal propensity to consume non-college goods that could reflect other spending priorities.

Altogether, our estimates are not particularly consistent with children forgoing college due to a lack of household resources alone. Specifically, the analysis reveals modest effects for wins sufficient to cover the cost of college and for households that are most likely to face constraints. ${ }^{9}$ In contrast, our results are consistent with households consuming college in part as a normal good, such that fundamentally altering a household's financial status can have a large impact on collegegoing, as the effects increase approximately linearly in the size of the win and reach a high upper bound. Indeed, some prior studies have found that the consumption component of education is larger for higher-income households, which is consistent with our heterogeneity analyses (including evidence of outsized effects at colleges with a greater focus on amenities and from neighborhoods with higher rates of college attendance). ${ }^{10}$

The paper is organized as follows. Section II introduces the administrative data used for analysis and examines the representativeness of lottery winners. Section III details the empirical design, the underlying assumptions, and presents falsification tests. Section IV describes the results, robustness, and extensions (including an investigation of heterogeneity and financial aid). Section V explores alternative household responses. Section VI discusses potential mechanisms. Section VII describes the relation of our findings to the literature. Section VIII concludes.

\footnotetext{
${ }^{8}$ In addition, we find that increases in financial resources during the calendar year of high school graduation have little effect on college attendance, which has implications for the design of policies seeking to improve college affordability (e.g., student aid offers and education tax credits).

${ }^{9}$ The muted response among children from more constrained households may partially reflect other factors, such as a lack of academic readiness for college, which we explore in Section VI.

${ }^{10}$ See Arcidiacono (2004), Alstadsæter (2011), Alter and Reback (2014), Jacob, McCall, and Stange (2018), and Gong et al. (2019).
} 


\section{Sample Construction and Lottery Winner Characteristics}

\section{a. Sample Construction}

We use the universe of federal tax records for the U.S. population to identify 1.5 million individuals who turned 18 between 1999 and 2013 and had a parent with a state-reported lottery win over those years. We then link their tax records to their college enrollment records, federal financial aid records, and parents' tax records using social security numbers. ${ }^{11}$ Throughout the analysis, dollar amounts are adjusted for inflation and denoted in real 2010 dollars.

To construct the sample, we first identify any individual with a state lottery win reported on the third-party reporting Form W-2G. This form is reported by the relevant state agency to the IRS, required for all prizes in excess of $\$ 600$, and first available in 1999. In addition to the amount of the win, the form indicates the state and year of the lottery. The first calendar year that we observe an individual receiving lottery income is designated as the "win year," which is used to classify household treatment. ${ }^{12}$ In a small fraction of cases, assumptions are required to identify the precise year or amount of an individual's first win. ${ }^{13}$ These ambiguous cases are excluded from the baseline sample, but we show that the estimates are robust to their inclusion.

To form "households," lottery winners are linked to their full set of tax records back to 1996 (the first year such data are available), which includes identifying information for any dependents they claimed on their tax return (Form 1040) over that window. Parent-child matches are only included if the child is claimed prior to the win, and, if the win occurred after the child turned 19

\footnotetext{
${ }^{11}$ Table A1 summarizes the merging process. The use of social security numbers as unique identifiers largely eliminates issues of mismatch. Of all lottery winners, 99.8 percent are linked to their Social Security Administration records, and 93.4 percent file a tax return as a primary or secondary filer prior to the win. Non-filers who win the lottery tend to be older, as retirees who depend on social security payments are not required to complete tax returns.

${ }^{12}$ Because we cannot observe whether lottery income received in 1999 is part of a multi-year payout stemming from an earlier win, we only include wins in the analysis that occurred in 2000 or later. The first win year is preferred because subsequent wins could be endogenous to the size of the initial win and hence contaminate the assignment of win size. The probability that a household experienced a large win prior to the first observable year, 1999, is small. To verify this, we note that only a small fraction of those with wins in the second half of the sample period experienced a large win in the first half and that estimates are robust to restricting attention to first wins that occurred in the second half of the sample period.

${ }^{13}$ This occurs when an individual is observed receiving supplemental income that matches their win amount in the year prior to state reporting (indicating that they may have been collecting the win before it was reported), when an individual has multiple wins in the same year and it is unclear which occurred first, and when a win is paid out over multiple years (which may not be fully observed during the sample period) and must be converted to a lump sum.
} 
years old, prior to turning $19 .{ }^{14}$ These links will include birth parents, step parents, and adoptive parents who are financially responsible for a child and whose income and assets are likely to be considered for the purposes of educational grants and loans provided by the federal government, states, and academic institutions. As an alternative to relying on claimed dependents to form our sample, we present results derived from birth parents as determined by Social Security Administration records.

The primary outcome of interest is whether children transition to college immediately after high school. We measure attendance with Form 1098-T data, a mandatory third-party reporting form filed by post-secondary institutions. This form yields each college and university a student attends in each calendar year starting in 1999. Both the act of and the timing of high school graduation may be endogenous to financial resources, so, consistent with the literature, the sample is not restricted to children who complete high school. We instead examine all children whose parents won the lottery, approximating the year of high school graduation using each child's exact birthdate (via social security card applications), the state in which the child was born, and the corresponding school entry age laws for that state. As Form 1098-T is filed by calendar year and not by academic year, children with 1098-Ts for their predicted high school graduation year are classified as transitioning to college immediately. ${ }^{15}$

We also examine the characteristics of colleges children attend as well as their financial aid receipt using data from the U.S. Department of Education. For the former, Form 1098-T data are linked by college identifiers to college characteristics maintained by the National Center for Education Statistics Integrated Postsecondary Education Data System (IPEDS), including whether the college is a two- or four-year and public, private, or for-profit institution. For the latter, we match via social security number student federal financial aid records within the National Student Loan Data System, an administrative database of student-level records describing their Title IV loans and grants. These data contain an array of financial aid information for each academic year, including application for aid (i.e., filing a FAFSA), subsidized and unsubsidized loan amounts, Pell Grant amounts, and expected family contribution (EFC), a Department of Education concept

\footnotetext{
${ }^{14}$ Claiming children after a win could be endogenous to the extent that tax filing and tax liability are influenced by lottery wins, and eligibility for claiming children aged 19 and over is mostly limited to those who are attending college.

${ }^{15}$ To address the concerns that this approach may misclassify some children's graduation cohorts (e.g., if they enter elementary school late or are held back) or count children that only briefly delay their matriculation to college as not attending, we present estimates using an alternative outcome variable which counts children as attending if they are enrolled in either their predicted high school graduation year or the subsequent year.
} 
that is designed to approximate a family's ability to pay for college. Because realized changes in aid can only be observed for federal sources, we supplement the analysis by imputing changes in state and institutional aid for our sample using restricted-use data from the National Postsecondary Student Aid Study (NPSAS), a research dataset that includes survey and administrative records of financial aid application and receipt for a nationally representative sample of students attending Title IV postsecondary institutions.

Finally, we examine several measures from tax records as outcomes of interest and draw on a number of pre-win child, parent, and household characteristics to test for balance in the research design, to include as controls, and to examine heterogeneity. Most notably, tax forms reveal earned income, investment income from interest and dividends, the presence of a mortgage, retirement contributions, and household composition. Many of the variables used are reported on Form 1040 and third-party reporting forms (e.g., W-2, 1099, 1099-int, and 1099-div), while some demographic information (e.g., gender, citizenship) comes from social security records. ${ }^{16}$ In addition to measures available in the tax records, the heterogeneity analyses split the sample by measures that are imputed using corresponding waves of the Federal Reserve Board's Survey of Consumer Finances (SCF), a triennial cross-sectional survey of U.S. families that includes information on their debt, assets, income, and demographic characteristics. Specifically, household liquidity, net worth, payment-to-income ratio, debt-to-asset ratio, propensity to be rejected for credit, and propensity to make late payments are all imputed from the SCF using a rich set of characteristics common to both datasets. Finally, heterogeneity by economic conditions is analyzed using business cycle timing and local measures of poverty, insurance coverage, and housing values from the U.S. Department of Agriculture, American Community Survey, and Zillow.

\section{b. Lottery Winner Characteristics}

The baseline analysis restricts the sample to children from families that experienced a lottery win within six years before or after their expected high school graduation (though we evaluate the robustness of the estimates to alternative windows).

Table 2 describes lottery wins and college attendance for the resulting population. Approximately 96,000 children are from households that win over $\$ 10,000$, nearly 14,000 are from

\footnotetext{
${ }^{16}$ Form 1040 is first available in 1996, and the first cohort of interest is 1999, so household characteristics are based on three pre-win years.
} 
households that win over $\$ 100,000$, and 1,300 are from households that win over $\$ 1,000,000$. Taking into account taxes reduces lottery win amounts by an average of 18 to 35 percent, with the reduction increasing in the size of the win. Only 3 to 4 percent of winners in any category subsequently win $\$ 10,000$ or more in a future lottery, easing concerns that households spend a significant fraction of their wins on additional lottery tickets or that total win amounts are misclassified. Approximately 35 percent of our sample attends college in their predicted high school graduation year (our main outcome of interest) and 45 percent attend by the following year (presented as an alternative specification). Table 3 indicates that, prior to a lottery win, the average household in the sample has wages of approximately \$52,000, and 57 percent of households file as married. The homeownership rate is about 56 percent, and slightly less than half of the households have interest or dividend income.

An important consideration for interpreting the estimates in this study is how representative lottery-winning households are of the population of U.S. households. As detailed in Appendix A, surveys indicate that up to 50 percent of the population plays the lottery. Further, lottery-playing households in the Consumer Expenditure Survey (CEX) closely resemble non-playing families in terms of family size, education, race, earnings, sector of employment, and assets, and they allocate \$266 (0.4 percent of annual spending) to buying lottery tickets (Table A2).

Given that our analysis examines lottery winners with children, we compare our sample to the population of tax-filing parents who have same-aged children. Relative to the parents in our sample, these parents have higher average earnings and are more likely to be married, though there is significant common support and their median earnings are nearly identical (Table A3). These results are consistent with other analyses of the comparability of lottery winners to a more-general population in the literature (e.g., Imbens, Rubin, and Sacerdote, 2001; Hankins, Hoekstra, and Skiba, 2011; Cesarini et al., 2017). While it is straightforward to account for differences in observable characteristics - we later show our results are robust to weighting the sample to resemble the overall population - one concern for generalizability specific to our setting is whether children from lottery-winning households have lower propensities to attend college due to unobserved factors such as academic readiness or parental support. To shed light on this, Table A3 also compares the enrollment rates of children whose parents won the lottery after they would have graduated from high school (and whose decisions to attend college were thus unaffected by the lottery wins) to the rates of same-aged children. This comparison reveals that, after 
conditioning on household characteristics, the children of lottery winners are only 1 percentage point less likely to attend college. In sum, while we cannot fully rule out differences in behavior and preferences, lottery winners appear to be only modestly different from non-winners in terms of observable characteristics and, once we account for these differences, the propensity of their children to attend college is nearly identical.

\section{Empirical Strategy}

Our empirical framework exploits within-state-year variation in both win size and timing. While the majority of the variation stems from the randomized process behind a lottery win, comparisons across win size alone would require an assumption that winners of different-sized payouts are not different along unobserved dimensions correlated with attendance. In our setting, variation in the payout is also an artifact of the type of lottery played and when the lottery is played, two factors for which it is difficult to control directly. (We are unaware of any state that collects data on the specific day and type of lottery tickets purchased by each individual, as tickets are sold by a variety of stores and are often paid for in cash.) Moreover, the prior literature has documented differences in the types of households that play particular lotteries (Oster, 2004), and, within our data, there are observable differences in household characteristics by win size.

To abstract from this assumption, we also leverage variation in the timing of wins with respect to the child's age. Specifically, we focus on outcomes that occur within a particular time frame relative to high school graduation and use the experiences of children who were "too old" at the time of the win to absorb unobserved differences between households that experience larger and smaller wins. For example, whether a child transitions to college immediately from high school cannot be affected by wins that occur in the years after high school graduation. ${ }^{17}$ The identifying assumption is that unobserved differences in the propensity to attend college across lottery win

\footnotetext{
${ }^{17}$ The main specification excludes wins that occur the year of high school graduation, although we demonstrate results are not sensitive to their inclusion. It is unclear if, and to what extent, children whose parents won that year can respond. A win in the fall is generally too late to change enrollment decisions. If the win occurs earlier in the year, it may also be too late to take the necessary steps to enroll in college (e.g., taking the SAT or ACT, meeting application deadlines), and the individual may have made other arrangements, such as taking a job or enlisting in the military.
} 
sizes are the same for children whose parents win before or after they graduate from high school. ${ }^{18,19}$

The sample includes wins as high as tens of millions of dollars; thus, how we choose to parameterize win size is important. For example, the effect of each dollar will necessarily decrease at some level, and a linear functional form will place the most weight on the largest wins. ${ }^{20}$ The baseline strategy addresses this issue via a flexible "step function" approach that categorizes wins into bins and thereby allows effects to vary across win ranges without imposing a strong functional form assumption. We classify wins according to five thresholds: $\$ 10,000, \$ 30,000, \$ 100,000$, $\$ 300,000$, and $\$ 1,000,000$. (We show that the results are not sensitive to these thresholds.)

The step function specification is:

$$
y_{i, c, s, y}=\delta_{s, y}+\delta_{c}+X_{i} \gamma+\theta \operatorname{PreHSG}_{i}+\sum_{j} \alpha_{j}\left(\operatorname{size}_{i}=j\right)+\sum_{j} \beta_{j} \operatorname{PreHSG}_{i}\left(\operatorname{size}_{i}=j\right)+\varepsilon_{i, c, s, y}
$$

The unit of observation is a child $i$ in a high school cohort $c$ in state $s$ and win year $y$. The specification includes state-by-year of win and expected year of high school graduation cohort fixed effects, with standard errors clustered at the parent winner level. $\boldsymbol{X}_{i}$ is a vector of 15 pre-win household and child characteristics. ${ }^{21}$ The $\alpha_{j}$ coefficients absorb fixed differences across households that experience different-sized wins, with wins between $\$ 600$ and $\$ 10,000$ (which average \$2,047) serving as the omitted group (though, in practice, the exact range of the omitted group is unimportant). The coefficient $\theta$ accounts for fixed differences between children who

\footnotetext{
${ }^{18}$ The identifying assumption would fail if, for example, the children of large lottery winners before high school graduation are differentially more college ready than children of small lottery winners relative to the difference in college readiness of children of large versus small winners after high school. The design does not require that children whose parents win before or after their high school graduation have identical propensities to attend college but rather that the differences are the same across lottery win sizes. Nonetheless, as reported in Appendix B, there is no significant shift in the income or share of households that win lotteries before or after their children graduate from high school.

${ }^{19}$ An additional assumption implicit in this analysis is that responsiveness to resources is similar for households across the win size distribution. We explore this assumption in Section IV(a) and Appendices B and C and find evidence that it holds.

${ }^{20}$ Issues with imposing linearity on the effects of income have been noted by Loken, Mogstad, and Wiswall (2012).

${ }^{21}$ These characteristics are log wages, log adjusted gross income, presence of mortgage interest, claiming of the selfemployment tax deduction, the presence of interest and dividends, the presence of SSA income (including disability), whether a 1040 is missing in any of the three years prior to winning the lottery (from which we derive these controls), household filing status, the number of children in the household, and parent and child gender and citizenship. Only households who do not file in any of the three years prior to the lottery win are excluded from the analysis. Data missing for a single year are treated as missing and are not assumed to be zero. Results are robust to alternative levels by which to cluster the standard errors.
} 
graduate before and after their parents experience a win. The key parameters of interest are the $\beta_{j}$ coefficients, which reflect the differential outcomes for children whose parents win a lottery of a given size relative to children whose parents won a small lottery, while accounting for fixed differences between these groups. A number of outcomes, each with a temporal component, are examined, including several variants of college attendance (e.g., sector-specific, level-specific, and different horizons relative to high school graduation), financial aid application and receipt, and parental labor force participation and savings.

In addition to the step function approach, we estimate two other specifications. The first relies on a continuous measure of win amounts, restricting attention to the range of wins over which the relationship appears to be linear (i.e., over which there is no evidence of concavity). ${ }^{22}$ While this specification requires a strong functional form assumption and is sensitive to the range of wins included, it yields a per-dollar effect that helps us compare estimates in a parsimonious manner across pre- and post-tax lottery win amounts as well as by household SES and other dimensions of heterogeneity. We also use this linear specification to estimate changes in parental earnings and other outcomes after the lottery win. The second specification is a multinomial logit model, which we use to further explore the margins of attendance across two- and four-year colleges and by household income.

Before turning to the main results, we examine whether the comparisons relied upon for identification appear to successfully isolate changes in resources. First, we test for balance by estimating the specification with 15 different exogenous pre-win characteristics on the left hand side. Table 3 presents the results across each characteristic, including adjusted gross income, selfemployment status, homeownership, and the presence of investment income (a proxy for savings). Among the 15 variables we consider, only 2 (self-employment and child gender) are jointly significant across win sizes at the 10 percent level, and among the 5 win size bins, none are jointly significantly different. An F-test across all win size bins and variables (the resulting 75 coefficients) is not significant ( $\mathrm{p}$-value $=0.5098$ ). ${ }^{23}$ Further, the design is balanced across the

\footnotetext{
${ }^{22}$ The linear specification is $y_{i, c, s, y}=\delta_{s, y}+\delta_{c}+\boldsymbol{X}_{i} \gamma+\theta \operatorname{PreHSG}_{i}+\alpha A m t_{i}+\beta$ PreHSG$_{i} A m t_{i}+\varepsilon_{i, c, s, y}$, where the win amount is measured in hundreds of thousands of dollars.

${ }^{23}$ As an alternative, we estimate the propensity of each child to attend college based on the 15 household characteristics (with the predictive importance of each characteristic estimated using older, unaffected children). We find that this measure of college propensity is insignificant across each win size bin and has an overall F-statistic of 0.4798. A similar balance test of the linear specification (not shown) reveals that 14 out of the 15 coefficients are insignificant, with the other significant only at 10 percent.
} 
household income distribution, college attendance and financial aid of older, unaffected siblings, and household characteristics when children are the same age (Tables A4 and A5). Altogether, there do not appear to be meaningful differences in observable child and household characteristics. Second, we conduct a placebo analysis that implements the design using only children whose parents won after their high school graduation year, reassigning the lottery win to a false prior year. This generates null effects, evidence that the timing of wins relative to high school graduation is not correlated with differential trends in college attendance across lottery win amounts (Table A6).

\section{The Effects of Household Financial Resources}

\section{a. College Attendance}

Figure 1 offers a graphical depiction of attendance rates pre- and post-lottery win by win amount. For resource shocks of less than $\$ 100,000$, differences in attendance by timing are small. In contrast, for larger wins, the differences are substantial, with the amount increasing in the size of the win. Note that children from households that experience larger wins are somewhat more likely to attend college, highlighting an identification challenge that, as Table 3 suggests, our design allows us to address.

We turn next to our main estimated effects of lottery wins on college attendance. Table 4 examines attendance in the year of high school graduation at any college, a four-year college, and a two-year college. The estimates reveal that moderate-sized shocks have little effect on attending any college. Wins between $\$ 10,000$ and $\$ 30,000$ and between $\$ 30,000$ and $\$ 100,000$ produce statistically insignificant effects, and we can rule out more than modest increases. For wins between $\$ 100,000$ and $\$ 300,000$, the coefficient is larger — on the order of 1 to 2 p.p.- but only marginally significant. The effect continues to increase above this level, with wins between $\$ 300,000$ and \$1,000,000 increasing attendance by an average of 5 p.p., and wins exceeding $\$ 1,000,000$ increasing attendance by approximately 10 p.p., and both estimates are highly significant. These estimates are stable to the inclusion of controls for household, parent, and child characteristics.

Differentiating the effects by college level reveals that they are driven by four-year college attendance. The four-year estimates closely mirror those for any college attendance, with no detectable change for small wins and the response increasing with the amount of the win. The 
estimates for two-year college attendance are small and statistically insignificant for all win levels. (For smaller wins, the lack of a two-year enrollment effect has a straightforward interpretation: even when we focus on schools that are relatively less expensive and less selective, modest shocks to resources have no material effect on attendance. The interpretation of estimates for larger wins is complicated by the fact that they represent the net effect of competing margins, as some children may be induced to attend a two-year college instead of no college, while others may be induced to attend a four-year college instead of a two-year college. ${ }^{24}$ ) In the interest of space, except where noted, the remaining analyses focus on four-year attendance.

Our results suggest that attendance effects are not very concave in the size of the win. An alternative explanation for the relative magnitude of effects across lottery win size is that they could be driven by treatment heterogeneity along a) observable characteristics that differ between large and small winners or b) unobservable differences by win size in the propensity of children to attend college. We test the former by reweighting households such that each win size bin has the same average characteristics (estimating similar results in Table A11 as from our main specification) and the latter by examining the attendance rates of older, unaffected children (finding no difference in college enrollment by win size once we condition on observable characteristics in Table A7). Thus, differences across win amounts are too modest to meaningfully alter the pattern of responses.

The estimates thus far represent average effects for ranges of wins, abstracting from strong functional form assumptions. To explore the shape of the response further, we first estimate a variant of the baseline specification, whereby we increase the number of bins more than tenfold, and fit a Lowess plot over the estimates (Figure 2). ${ }^{25}$ The effect appears to be approximately linear until win sizes reach nearly \$5,000,000 and reach an upper bound of around 20 p.p. Then, Table 5 specifies win size continuously, interacting the amount of the win with whether the win occurred prior to high school graduation. The first column tests for concavity by including a linear and quadratic term and imposing various caps on the largest win size included in the sample. Consistent

\footnotetext{
${ }^{24}$ Because these competing margins cannot be observed directly, we examine if there are changes in the average characteristics of households with children attending two-year colleges. The resulting estimates (not shown) reveal no evidence that characteristics are changing, which is more consistent with no gross effects on attendance at two-year colleges.

${ }^{25}$ Bin increments are selected as follows: $\$ 5,000$ up to $\$ 100,000, \$ 25,000$ up to $\$ 500,000, \$ 100,000$ up to $\$ 1,000,000$, and $\$ 500,000$ up to $\$ 5,000,000$. Effect sizes are estimated relative to small wins of less than $\$ 1,000$.
} 
with the figure, the coefficient on the quadratic term is indistinguishable from zero when restricting attention to wins less than $\$ 5,000,000$ (and any threshold below), suggesting little concavity in this region. ${ }^{26}$ Note that the challenge of imposing a specific functional form on lottery wins is reflected in the sensitivity of the linear estimates to including large wins in the analysis. Because of the above findings, we only include lottery wins that are less than $\$ 5,000,000$ when estimating the linear specification.

The linear specification facilitates comparisons across alternative constructions of key variables. Table 6 presents estimated linear effects of lottery wins on four-year college attendance before and after adjusting for income taxes, after broadening the enrollment measure to include the subsequent year, and as an elasticity with respect to average annual and total household income during childhood. The estimated linear effect is approximately 0.6 p.p. per $\$ 100,000$ of pre-tax lottery winnings. To predict after-tax lottery winnings, we take each household's pre-win tax return, add the lottery win, and apply the lottery year's tax rules. This simulated tax liability approach produces an average reduction in the take-home amount of 30 percent. The resulting effects are commensurately larger, with attendance increasing by 0.9 p.p. per $\$ 100,000$ of post-tax winnings. Table 2 indicated that approximately 10 percent of children initially enroll in college in the year after their predicted graduation, potentially due to factors such as entering elementary school late, being held back, not meeting graduation requirements, or choosing to delay matriculation. Thus, we replicate the design while expanding the definition of enrollment to include the year of expected graduation and the subsequent year, and find a similar-sized effect of 0.7 p.p. per $\$ 100,000$. Estimating the response as an elasticity reveals that attendance increases by 0.22 percent for each 1 percent increase in total household income during childhood. In the appendix, we consider an alternative method of measuring treatment intensity. Parents may share lottery wins across children, and we find some evidence of smaller effects for households with more children (Table A29). Thus, we divide the win equally across children and estimate a win amount per child effect. This approach scales the estimate proportionally, resulting in an average increase in attendance of 1.2 p.p. per $\$ 100,000$.

\footnotetext{
${ }^{26}$ Table A8 presents an alternative test of linearity across win amounts. Incorporating indicators for win size bins into the linear specification reveals that they are not statistically significant, implying that the linear coefficient is sufficient to capture the relationship between the lottery win and the college attendance response. We also estimate the degree of concavity while taking into account aggregate household income during childhood (using parents' pre-lottery average AGI multiplied by 18 as a proxy). The results (not shown), which load treatment heterogeneity, suggest linearity up to $\$ 10,000,000$ in resources.
} 
Figure 3 plots estimated differences in attendance between children whose parents won large versus small lotteries on a year-by-year basis both before and after the children graduate from high school—where "large wins" in the top panel are defined as wins greater than $\$ 100,000$ and "large wins" in the bottom panel wins greater than $\$ 300,000$ (excluding those between $\$ 100,000$ and $\$ 300,000)$ —and reveals several key results. First, estimated differences are generally positive for children whose parents win the lottery in any of the six years prior to their high school graduation year but not for children who graduate prior to the win. This pattern affirms the timing exploited by the design. (Table A10 further confirms the sharpness of the pre-post transition by replicating the baseline specification while sequentially reducing the window of lottery win years before and after graduation.) Second, the magnitudes are similar across years, so effects do not appear to grow or diminish depending on the time between a lottery win and high school graduation. And third, the steep drop-off in effects in the year of high school graduation suggests that the year in which policies that seek to improve college affordability become salient to households is material to their effectiveness.

The pattern and magnitude of the results are robust to a number of alternative methods of classifying treatment and constructing key variables (described more fully in Appendix C). The estimates are stable when linking children to their birth parents and when using alternative win ranges for the control and treatment groups. ${ }^{27}$ The results are also robust to designs based solely on lottery win sizes or the timing of the wins relative to high school graduation (Tables A15 and A16) ${ }^{28}$ Using the lottery win to instrument for a household's net change in income as a way to take into account any corresponding changes in household earned income in response to a win also reveals an average effect of 0.6 p.p. per \$100,000, suggesting any such responses are small relative to the win amount (Table A17). Restricting attention to within-household comparisons of siblings results in estimates that are similar in magnitude but less precise than those in the primary design. ${ }^{29}$

\footnotetext{
${ }^{27}$ Estimates for alternative samples and control groups are presented in Table A11 and narrower win ranges in Table A12. In addition, we present estimates for alternative measures of college enrollment in Table A13 and levels of clustering in Table A14.

${ }^{28}$ An across win size design produces estimates of 2, 5, and 8 p.p. for the largest three win size bins, while a design exploiting only the timing of the win generates effects of 1, 5, and 11 p.p. (Tables A15 and A16). The linear estimates (not shown) for these designs are 0.5 and 0.6 p.p. per $\$ 100,000$, respectively. Neither the binned nor the linear estimates are statistically significantly different from those in the primary design.

${ }^{29}$ Within-household comparisons require that at least one child graduates before and after the win. As shown in Table A11, this discards 74 percent of the sample, including all one-child households, significantly reducing precision and placing greater weight on households with many children. These estimates are not statistically different from those in
} 
From the magnitude and pattern of results thus far, it appears unlikely that a large fraction of students are deterred from attending college solely due to binding borrowing constraints at the household level. Nonetheless, the estimates reveal a role for household resources in shaping college outcomes. The average effect of a pure resource shock in our context explains about onethird of the 1.7 p.p. per $\$ 100,000$ relationship between four-year college attendance and total childhood household income observed in the cross-section (Table 1). Likewise, the 10 p.p. effect found for the largest win bin represents a 30 percent increase in any college attendance and a 50 percent increase in four-year college attendance with respect to baseline rates in our data. To put this in perspective, this effect matches the overall growth in the attendance rate that occurred during the rapid expansion in college enrollment between the late 1970s and the mid 1990s.

b. Enrollment in Later Years and by College Type

Additional household financial resources could raise children's enrollment in years after high school graduation, increase time in college, or change the types of colleges attended. Table 7 presents the effects of lottery wins on enrollment in the four years after high school graduation, as well as the cumulative change in years of attendance over this period. Following the logic of our main specification, the control group is restricted to children whose parents won after the year being analyzed and thus could not have been affected by the win. ${ }^{30}$ For smaller wins, there is no evidence of increased attendance in any year or total years in college. However, large wins increase attendance in each of the four years after high school graduation and raise cumulative attainment by as much as 0.6 year. Thus, it does not appear to be the case that wins generate a temporary increase in attendance that rapidly fades. Still, these effects could partially reflect increased persistence among students who would have initially attended regardless of the lottery win.

Table A19 extends the analysis to examine if children are induced to attend college by wins that occur after high school graduation. Replicating Table 4 for children whose parents won in the four years after their expected high school graduation and similarly restricting the control group to children whose parents won after the year being analyzed indicates that effects are attenuated

the primary step function design, with joint test p-values of 0.29 and 0.70 , nor do they differ when we estimate the effects in a linear specification.

${ }^{30}$ Table A18 replicates this design, restricting the control group to those whose parents won the lottery four or more years after high school graduation. While this eliminates the children who are most similar in terms of win timing, it maintains a consistent control group across each post-high school year analyzed. The results are similar. 
for later wins, suggesting that attendance behaviors are more meaningfully influenced by resource shocks that occur before children graduate from high school. ${ }^{31}$

Turning to college composition, we do not find a clear shift in the sector of attendance for smaller wins, so the lack of an effect on overall attendance is not obscuring offsetting changes in private and public college attendance (Table A21). Likewise, when we examine college quality (measured either as a binary variable denoting whether college attendees have above median earnings or as the average earnings of attendees), the effects for smaller wins are not statistically significant. For wins less than $\$ 1,000,000$, the enrollment effects are concentrated at public colleges, while wins exceeding $\$ 1,000,000$ increase enrollment at both private and public colleges, and at colleges whose attendees subsequently have higher earnings.

c. Heterogeneity

Households of varying means and financial constraints might differ in their responsiveness to resource shocks. For example, households may differ in their access to credit, their consumption preferences, or the extent to which their children are college ready. Table 8 presents tests for heterogeneous effects on four-year attendance using the linear specification and, one-by-one, interacting the pre-college win amount term with various measures of constraints. Throughout the table, the coefficient on the interaction term quantifies the differential effect for the less constrained group.

The top panel delineates households based on financial characteristics available in (or that can be imputed from) the tax data, measured prior to the lottery win. The first column reveals a large and statistically significant coefficient on this term, indicating that children from households that have above the median income in our sample (about $\$ 45,000$ ) appear to be driving the positive effect of lottery wins on attendance. This result is also evident in the step function specification and a multinomial logit model. ${ }^{32}$ Responses are also statistically larger for households that have

\footnotetext{
${ }^{31}$ Only the largest wins generate a statistically significant increase and only for any college enrollment. Tables A20 shows there are no notable attendance effects among parents.

32 Table A24 presents the step function specification for households with incomes above and below the sample median $(\$ 45,000)$. The estimates do not reveal significant changes in enrollment at two-year colleges for lower- or higherincome households. The effects for larger wins are concentrated at four-year colleges and above median income households. Though sizable four-year college responses to the largest wins cannot be ruled out for lower-income households due to a lack of precision, the estimates are statistically significantly smaller. These results are confirmed by a multinomial logit model that simultaneously estimates two-year and four-year attendance for lower- and higher income households (Table A25). Tests of heterogeneity by household income are unchanged after adding terms
} 
interest or dividend income (a proxy for savings), make voluntary retirement account contributions (given their tax advantages, those who do not contribute to them are more likely to be financially constrained), and for households with above median wealth, which is estimated following Saez and Zucman (2016). ${ }^{33}$ There does not appear to be a differential effect in either direction for homeowners.

The effect of financial resources on attendance may vary along other segments of the income distribution or administrative measures of ability to pay for college (Belley and Lochner, 2007; Stinebrickner and Stinebrickner, 2008; Lochner and Monge-Naranjo 2011; Brown, Scholz, and Seshadri, 2012; Johnson, 2013; Cowan, 2016; Marx and Turner, 2018). A more refined split by household income reveals that enrollment responses are modest for the lowest two quartiles of household income, and are larger and statistically significant for the top two quartiles (Table A27). After applying the federal aid formula to each household's pre-win income, imputed wealth, and composition to predict the administrative measure of ability to pay for college (i.e., its EFC), we find larger enrollment responses for households with a higher ability to pay and for those with too high of an ability to pay to receive a Pell Grant.

To capture other aspects of a household's financial position, we use the Survey of Consumer Finances (SCF) to construct measures of the probability a household has been denied credit, the probability a household has made late payments, whether a household has high debt service (in relation to its income or assets), and whether a household has low liquidity. ${ }^{34}$ Across each of these measures, less constrained households are more responsive to lottery wins. Finally, the bottom panel of Table 8 differentiates the effects by local poverty rates, health insurance coverage, and housing values as well as the business cycle (as the Great Recession years of 2008 to 2012 represented a period of particularly tightened access to credit). These aggregate measures could capture household constraints that are not evident in the tax data, but reveal no evidence of larger effects for households that live in more disadvantaged communities or whose children graduated

\footnotetext{
allowing for heterogeneous responses by investment income, homeownership, and debt cancellation status (Table A26).

33 See Appendix D for a discussion of how wealth is imputed using tax variables.

34 The SCF includes questions about whether or not a household has been denied credit or deterred from applying for credit in the last year (Japelli, 1990; Crook, 1996; Japelli, Pischke, and Souleles, 1998; Bostic, Gabriel, and Painter, 2009). It also includes information about average monthly payments, late payments, debt, and assets. Appendix D presents the procedure used to impute these values for households in our sample using variables that are observable in both the tax data and the SCF such as earned income, business income, investment income, retirement accounts, homeownership, marital status, and household size.
} 
from high school during the Great Recession. (Table A23 presents more refined splits, by comparing the top to bottom quartile for each non-binary measure of being constrained from Table 8. This division also generally reveals a pattern of larger responses for the least constrained households relative to the most constrained households.)

The tax treatment of lottery wins and more expansive definitions of enrollment may be especially relevant for heterogeneity analysis, as lower-income households face lower marginal tax rates and their children are less likely to graduate from high school on time. Replicating the linear design for post-tax win amounts reveals that effects are again concentrated at higher incomes, with little evidence of changes in enrollment for households with below median income (Table A28). Results are similar when the effects of lottery wins are measured as the elasticity of college attendance with respect to annual or lifetime income. More notably, the effects for lower income households become marginally significant under the broader definition of enrollment; still, they are only one-third as large as those for higher income households. Extending the heterogeneity analysis by income to the types of colleges attended, the estimates for children from higher-income households fully mirror those using all households from earlier, while there is some evidence that very large wins increase public enrollment for lower-income households (Table A30).

We next build on Figure 3 and further examine heterogeneity by win timing. If additional resources are spent down prior to the college transition and are unavailable to cover tuition (though we later do not find evidence consistent with this phenomenon), then the effects of earlier wins could be muted. Alternatively, if parents are financially constrained from allocating income to inputs that are complementary to college-going (e.g., if there is a critical period for investment at younger ages), then earlier resource shocks could produce larger effects. ${ }^{35}$ Table 9 presents a specification that includes the interaction of a time trend, an indicator for whether the win occurred prior to graduation (i.e., treatment), and a continuous measure of the lottery win amount. The resulting coefficient on the fully interacted trend is statistically indistinguishable from zero, which, consistent with the earlier evidence, suggests equally large effects across the six years prior to high school graduation. Column 2 examines resource shocks earlier in childhood by expanding the

\footnotetext{
${ }^{35}$ A large literature has found significant effects of in-kind early childhood resources, including parental leave generosity (e.g., Dustmann and Schonberg, 2012; Carneiro, Loken, and Salvanes, 2015) and preschool programs (e.g., Deming, 2009; Heckman, Pinto, Savelyev, 2013). See Almond, Currie, and Duque (2018) for a recent assessment of the literature. Our context lacks the statistical power to generate precise estimates for income shocks affecting very young children. However, we are able to test for strong trends across the 14 years prior to high school graduation.
} 
sample to include all children from households that won the lottery prior to their high school graduation that we can observe in our sample period. ${ }^{36}$ The interaction term of interest is insignificant, indicating positive effects of similar magnitude across children aged 3 to 17 . The final two columns combine the analyses by SES and timing and test, in both the baseline sample and the expanded sample, whether earlier wins generate relatively larger responses among lowerincome households, which would be expected if borrowing constraints were inhibiting important earlier investments. There is no evidence that earlier wins generate larger (or smaller) effects for lower-income households.

\section{d. Federal Financial Aid}

Enrollment responses to lottery wins may be attenuated by the crowding out of financial aid. In particular, additional resources may reduce need-based assistance for children from lower-SES households. We first descriptively examine changes in financial aid within our design, revealing that the largest lottery wins reduce FAFSA application rates (despite higher rates of attendance), and wins of all sizes increase the average expected family contribution used for determining aid eligibility, and reduce loan and grant amounts (Table A32). ${ }^{37}$

To investigate if crowd-out of aid is meaningfully moderating our attendance estimates, we leverage a useful institutional feature of the primary formulas used for financial aid determination - that the marginal effective tax rate for parents' income can be quite high (20 to 50 cents on the dollar) whereas the effective tax rate for assets is far lower (several cents on the dollar) (Dynarski, 2004). ${ }^{38}$ These rates imply a substantially different loss of aid depending on whether or not the win occurred in the year before high school graduation and is thus counted as income for determinations of financial aid eligibility for the first year of college (the "FAFSA Year"). To

\footnotetext{
${ }^{36}$ Figure A2 presents estimates for wins that occur in each of the 12 years prior to high school graduation. The point estimates in each treated year are positive and there is no clear change in magnitude across wins affecting younger and older children. Due to data limitations, the effects of wins in early childhood are not precisely estimated.

${ }^{37}$ This analysis is descriptive in nature because financial aid outcomes are endogenous to, among other things, college attendance, composition of attendees, aid application, and parental responses to lottery wins that affect income and asset holdings. There is no significant change in taking tax credits or deductions for tuition in response to lottery wins. In contrast to federal aid, eligibility for tax benefits is not a direct function of wealth (other than through investment income) and phases out at much higher income levels.

38 There are two formulas used to determine aid eligibility, the Federal Methodology (FM) and the Institutional Methodology (IM). The FM, used by the Federal Government and most colleges, relies exclusively on information from the FAFSA, while the IM, used by some private colleges, relies on the FAFSA and supplementary information such as home equity. Both formulas treat assets much more favorably than income: the FM assesses parental income up to 47 percent and assets up to 6 percent, and the IM assesses parental income and assets up to 46 and 5 percent, respectively.
} 
exploit this feature, we re-estimate Pell Grant receipt, first excluding and then restricting attention to wins that occurred the year before a child graduates from high school. As shown in Table 10, when lottery wins that occur in the FAFSA Year are excluded, grant reductions are small, but when attention is restricted to this year, the crowd-out of grants is large, especially for lower-income households. (Likewise, Table A33 shows imputed changes in state and institutional aid are concentrated in the FAFSA Year. ${ }^{39}$ ) However, the pattern of attendance estimates when excluding and restricting attention to the FAFSA Year are similar to the baseline estimates, both on average and for lower-income households.

Still, effects in the FAFSA Year may not be fully comparable to effects in all other years if there is treatment heterogeneity in the timing of the win. (Note that the prior results on timing are not prima facie consistent with such heterogeneity.) To consider this possibility, we test for a differential effect in the FAFSA Year after adding a linear time trend interacted with the interaction of amount of the win and whether the win occurred before high school graduation. The differential effect is small and statistically insignificant in all cases for the FAFSA Year (Table A34), including when examining only lower-income households. Altogether, these results imply that while a reduction in financial aid is a natural byproduct of winning the lottery, crowd-out does not attenuate the overall effect or explain heterogeneous responses observed across the income distribution. ${ }^{40}$

\section{Alternative Household Responses}

Households may also respond to resource shocks by altering their labor supply, savings, homeownership, and geography. To provide context for the college enrollment estimates against other potential spending priorities, we probe effects on these outcomes. Further, to shed light on

\footnotetext{
${ }^{39}$ Because the observed financial aid outcomes are restricted to federal sources, we impute the effect of lottery wins on state and institutional aid for all households in the sample using the NPSAS. Appendix D presents details of the imputation procedure.

${ }^{40}$ These results do not imply that college enrollment is unaffected by financial aid more generally due to several mitigating factors. First, the change in aid is concurrent with a large increase in household financial resources, resulting in an atypical context for evaluating price effects that must assume that effects of resources and aid do not interact. Second, the resulting changes in aid from the resource shock may be exceptionally difficult to anticipate. And third, the exercise does not produce a precise enough estimate of the difference in attendance scaled by the loss of aid in the FAFSA Year relative to other years to rule out changes that are consistent with the price effects literature.
} 
the external validity of lottery wins, we explore the degree to which observed household responses to lottery income are unusual.

\section{a. Main Effects on Non-College Outcomes}

Table 11 presents estimated effects on parental outcomes. For consistency, each outcome is examined within the same framework as attendance, focusing on the year a child graduates from high school. The labor supply results reveal evidence of reduced earnings, and, for larger resource shocks, a reduction on the extensive margin. ${ }^{41}$ Interestingly, we find little effect on selfemployment earnings. Perhaps the (implied) increase in leisure among lottery winners offsets the relaxation of financial frictions. ${ }^{42}$ Large wins also generate increases in savings (i.e., interest and dividend income), but the effects of lottery wins for homeownership are more nuanced. For those without a mortgage prior to winning, there is an increase in having a mortgage even for moderatesized wins, with the size of the effect increasing to 25 p.p. for very large wins. For those with mortgages already, households appear to use large wins to pay them off. All told, homeownership appears to be a significant spending priority. Households with large wins also move to slightly wealthier neighborhoods and those with modestly higher rates of college-going. However, when neighborhoods are classified on the basis of mobility by county (Chetty and Hendren, 2018), there is no evidence that these moves are to areas with greater upward mobility.

Table A36 briefly explores effects on children's labor supply. Results indicate that lottery wins reduce earnings in the year after high school graduation, with the effects increasing in the size of the win, broadly consistent with the pattern we saw earlier with respect to college attendance. That said, there is little evidence of an effect along the extensive margin, except in the largest win category, indicating that they are generally still employed in some capacity but less intensively than in the counterfactual state. ${ }^{43}$ Note that, beyond a reallocation of time from work to college, the earnings reduction may partly reflect increased consumption of leisure. The final column

\footnotetext{
${ }^{41}$ The linear specification in Table A35 reveals that households reduce annual earnings by $\$ 1,170$ in response to a win of $\$ 100,000$. This is consistent with the estimate in Cesarini et al. (2017), which finds that earnings decrease annually by 1 percent of the prize amount in Sweden. Imbens, Rubin, and Sacerdote (2001) estimate elasticity of earnings with respect to payments of -0.10 match our estimates under the assumption of a discount factor of approximately 9 percent.

${ }^{42}$ Evidence in the literature on the effect of resource shocks on self-employment is mixed. While Holtz-Eakin, Joulfaian, and Rosen (1994), Lindh and Ohlsson (1996), Taylor (2001), and Andersen and Nielsen (2012) find positive effects, Cesarini et al. (2017) find a negative effect on self-employment and self-employment income.

${ }^{43}$ This is consistent with the finding in Keane and Wolpin (2001) that relaxing borrowing constraints does not change attendance decisions but does cause students to work less while they are enrolled.
} 
examines children's earnings several years down the road—when they are 27 years old—with the pattern of results consistent with children induced to attend college by a lottery win having higher earnings in early adulthood, though the estimates are too imprecise to be conclusive. ${ }^{44}$

b. Persistence of Household Responses to Lottery Wins

While in standard economic models, a household's response to a resource shock does not depend on its source, in practice, one may be concerned that households differentially allocate prize money in a manner that could lead our estimates to misstate the effect of resources more generally on college attendance. (See Appendix E for a full exposition of this analysis.) In particular, households might “over-consume” lottery winnings, resulting in few resources being available for potentially high return college investment. A rapid depletion of lottery wins would manifest itself in short-lived changes in wealth and parents' earned income (and the presumed impact on leisure). Figure 4 and Table A38 examine the persistence in response in each of the five years following a lottery win for wealth, earnings, homeownership, and debt cancellation. Using our tax capitalization measure of household wealth, we find that approximately half of the posttax lottery win is retained as wealth after five years. Further, estimated effects on earned income and new homeownership are stable over time, consistent with the predictions of a wealth shock in a standard lifecycle model. In the final column, we examine debt cancellation (a proxy for bankruptcy) — whereby increasing coefficients over time could signal that lottery winners are overspending, falling behind on payments, and going bankrupt—and instead observe a modest and persistent reduction in debt cancellation. These findings echo Cesarini et al. (2017), which finds evidence of persistent changes in earnings and wealth in response to lottery wins in Sweden. The estimates are also consistent with our earlier findings that enrollment effects persist over the four years after high school and are not concentrated among wins occurring shortly before high school graduation. Overall, we find evidence that supports the generalizability of our lottery-win-based estimates to other types of resources. ${ }^{45}$

\footnotetext{
${ }^{44}$ We examine the earnings of 27 years olds as a compromise between selecting an age that is correlated with laterlife earnings and restricting the size of the sample. Note that, by this point, all children in the sample will be "postwin,” although comparisons are still derived by the timing of the wins relative to high school graduation.

${ }^{45}$ We similarly find that, by examining the effect of lottery wins on the ownership of businesses and other risky assets in Table A39, households do not appear to be averse to investing their winnings in enterprises with relatively uncertain returns (which are similar to college in that respect).
} 


\section{Potential Mechanisms}

This section describes two leading (non-mutually exclusive) mechanisms that might explain why additional resources influence attendance and whether our findings are consistent with each. ${ }^{46}$

First, households may face financial frictions — such as a lack of access to credit or aversion to debt- that restrict college access for children who would otherwise earn high returns. ${ }^{47,48}$ Much of the structural literature finds evidence that only a small fraction of households are constrained from sending their children to college due to late-stage financial factors alone (Cameron and Heckman, 1998, 2001; Keane and Wolpin, 2001; Carneiro and Heckman, 2002; Cameron and Taber, 2004; Caucutt and Lochner, 2020). However, the rising cost of college and limited growth in the generosity of federal aid has increased reliance on private borrowing and may have increased the role of constraints (Belley and Lochner, 2007; Lochner and Monge-Naranjo, 2011).

If binding financial constraints restrict college access for children from a significant fraction of households, the estimated effect of an income shock on college-going would likely be concave, with moderate increases in resources leading to economically significant increases in attendance. For example, median tuition and room and board in 2011 was about \$7,800 at two-year public colleges and \$16,900 at four-year public universities, while average debt among four-year public college graduates was $\$ 25,600{ }^{49}$ Thus, a $\$ 50,000$ lottery win should eliminate the need to incur debt for most students; moreover, a $\$ 100,000$ win is sufficient to fully cover four years at the

\footnotetext{
${ }^{46}$ We assess each explanation in isolation. While there are other potential mechanisms, they are unlikely to be primary explanations for the relationship we obtain. For example, additional resources could increase attendance by insuring against the risk of college investment. The results are not prima facie consistent with such an explanation, as effects would likely be larger among lower-SES households than higher-SES households, but we cannot rule out that complementarity between parental resources and children's attendance is a factor (though we would again expect similar heterogeneity responses).

${ }^{47}$ In addition to financial returns, a number of non-pecuniary returns to college may be valued by prospective students, including improved health, marriage opportunities, and workplace quality and benefits (Hamermesh, 1999; Pierce, 2001; Glied and Lleras-Muney, 2008; Chiappori, Iyigun, and Weiss, 2009; Silles, 2009; Oreopoulos and Salvanes, 2011; Lafortune, 2013).

${ }^{48}$ The U.S. is not unique in having a strong correlation between household SES and the college outcomes of children. Among the 32 OECD countries, the U.S. has the 13th largest gap in tertiary enrollment between children whose parents did or did not attend college (OECD, 2017). However, the U.S. is exceptional in terms of its high tuition levels and the fraction of educational costs that are borne by households; it has the highest average college tuition levels and the 3rd highest share of tertiary education funded by households rather than by public sources. Thus, the context of our analysis is one in which the role of household resources is not mitigated by universal subsidies for higher education. In many other countries, intergenerational persistence is unlikely to stem from the cost of college, but rather may be due to tracking into college and non-college streams at an early age (Orr et al, 2017; Crosier et al., 2018).

${ }^{49}$ Table A40 presents the distribution of tuition by college type, and Table A41 differentiates average costs and parental support by household income.
} 
median college, even after taxes have been deducted. If attendance is deterred by a lack of cashon-hand for incidental expenses, then even smaller resource shocks could be sufficient to generate a response. ${ }^{50}$ However, the results are only weakly concave, and $\$ 100,000$ is estimated to increase college going by less than one percentage point.

Further, if binding financial constraints were a primary factor in deterring college, we might expect the most financially constrained households to be the most responsive. Yet, households that have low income, low wealth, and are most likely to be denied credit seem, if anything, less responsive than other households. Reductions in financial aid that result from the lottery win and adversely affect constrained households the most do not appear to explain this difference. Likewise, some lower-income parents appear to reduce their labor supply in response to a win, which would be unusual if they were very financially constrained. Note that a variant of this mechanism - that households face financial constraints, but they bind earlier by limiting parental investment that is complementary with college-also appears to be inconsistent with the estimates. ${ }^{51}$ Specifically, when we expand the sample to include a wide range of win timing prior to high school graduation, the effects are relatively stable, and earlier resource shocks are no more important for lower SES households. In sum, a "financial frictions" explanation does not appear to fit the overall pattern of results.

Second, households may derive consumption value from college, much as they do from normal goods. The consumption value of education has long been hypothesized in the literature, incorporated in human capital models, and is often needed to fit the data (Schaafsma, 1976; Lazear,

\footnotetext{
${ }^{50}$ Some prior literature, including Stinebrickner and Stinebrickner (2008), Lochner and Monge-Naranjo (2011), and Cowan (2016), consider how, while loan and grant programs help finance the direct costs of attending school, prospective students may have difficulty smoothing non-schooling consumption. Consistent with increased resources reducing constraints on non-schooling consumption, we find in Table A36 a reduction in earnings among belowmedian income college students (who we can examine because there is no evidence of selection into college due to lottery wins). Still, reducing any such constraints does not appear to increase their attendance outcomes by much.

${ }^{51}$ We note three caveats: 1) we cannot test for very early life constraints, 2) our results are not inconsistent with an under-investment in schooling deriving from financial frictions in combination with other features, raising the possibility that policies that relax both financial constraints and, for example, informational frictions may still be effective, and 3) one piece of evidence that could be consistent with constraints inhibiting high return investment that is complementary with college is the finding that lottery winner's move to modestly wealthier and more educated neighborhoods. With respect to the third caveat, the effect on neighborhood could also be due to a consumption story (or possibly both) and appears too small to explain more than a fraction of the main effect (namely, even under the strong assumption that children adopt the same college-going rate as those from their new neighborhood, such neighborhood effects could explain only a fraction of the primary estimates). We also note that, while earlier wins may allow greater complementary investment, the additional resources from a lottery win may have been partially spent down by high school graduation, thus creating offsetting effects.
} 
1977, Kodde and Ritzen, 1984; Eckstein and Wolpin, 1999; Keane and Wolpin, 1997, 2000; Carneiro and Heckman, 2002). More recent empirical research has documented evidence in the context of college (Arcidiacono, 2004; Alstadsæter, 2011; Alter and Reback, 2014; Jacob, McCall, and Stange, 2018, Gong et al., 2019). Predictions from a consumption channel are consistent with our findings. Namely, we would expect to see college attendance increasing in the size of the resource shock, with a high upper bound that is achieved at values that exceed the cost of college, which is indeed what we observe. We also find evidence of a disproportionate increase in attendance at four-year colleges that are likely to have higher consumption value, which we measure using the level of student services spending and the ratio of student services to total spending in the style of Jacob, McCall, and Stange (2018), and in zip codes with higher rates of college attendance (even conditional on zip code average income). ${ }^{52,53}$

That said, a potential tension with a consumption-based interpretation of our results is that typically one would expect lower-SES households to have a higher marginal propensity to consume, yet the heterogeneity analysis finds larger effects on attendance among higher-SES households. ${ }^{54}$ However, there is evidence in the literature that higher income households may derive more consumption value from education (e.g., Carneiro and Heckman, 2002; Jacob and Lefgren, 2007; Jacob, McCall, and Stange, 2018) and that parental willingness to provide support for college may increase with SES (e.g., Brown, Scholz, and Seshadri, 2012), which could mean that lower-SES households have higher marginal propensities to consume but simply derive relatively more marginal utility from non-college consumption. To analyze differences in the marginal propensity to consume by SES, we implement an accounting exercise that digs deeper into key non-college outcomes. Specifically, under the assumption that the residual of earnings and savings responses to lottery wins is a consumption response, Table 12 explores potential

\footnotetext{
${ }^{52}$ The details of these exercises are presented in Appendix G. The estimates in Table A42 reveal statistically significant increases in attendance at colleges with higher levels of student services spending. These effects are driven by children from households with above median incomes. Table A43 presents evidence that attendance responses are larger for households residing, prior to the win, in communities with higher rates of college attendance (which could reflect unobserved preferences for consuming education), even after accounting for heterogeneity by average income in the community.

${ }^{53}$ The consumption value of college may accrue to children and/or parents. If it primarily accrues to parents, they may use college-contingent transfers to induce their children to attend, creating a direct link between parental resources and children's college choices (e.g., Keane and Wolpin, 2001; Weinberg, 2001; Brown, Scholz, and Seshadri, 2012). ${ }^{54}$ Several studies examining tax rebate windfalls document higher rates of spending for lower-income households (Souleles, 1999; Johnson, Parker, and Souleles, 2006; Parker et al., 2013) and others find no, or an opposite signed, difference (Shapiro and Slemrod, 1995, 2003; Parker, 1999; Agarwal, Liu, and Souleles, 2007).
} 
heterogeneity in effects on earnings and savings by pre-win household income. ${ }^{55}$ In addition to smaller increases in college-going, lower-income households have both a smaller earnings reduction and smaller savings increase, suggesting that, even though they are less responsive with respect to college attendance, such households consume a higher fraction of their lottery winnings. $^{56}$

Several factors may help to explain why lower-SES households appear to place lower consumption value on college (or, more generally, be less responsive along this margin). First, children from lower-income households are less likely to be college ready than their higher-income peers. ${ }^{57}$ While three-quarters of students from below median income households graduate from high school on time, less than half satisfy each of three measures of academic readiness that are highly correlated with college enrollment in the Education Longitudinal Study: graduating on time, having a 2.0 or higher GPA, and scoring above the bottom quartile on the PISA test (Table A44). To try to adjust for differences in college readiness, we scale the estimates by the fraction of students who could feasibly be induced to attend college based on several measures of readiness across the household income distribution. Scaling produces larger average treatment effects but does not eliminate the statistically significant gap by household income (Table A45). Second, prior to the win, lower-income households likely faced higher borrowing costs for other forms of consumption, thus altering the relative returns of allocating resources toward college versus paying off debt. Indeed, the SCF confirms that credit card and mortgage interest rates are modestly negatively correlated with income, although lower-income households have less debt on both the

\footnotetext{
${ }^{55}$ Specifically, one can simply assume a consumption response = winnings + earnings response - savings response. For the purposes of this exercise, we are interested in the level effect on earnings, not the relative effect (which could be a proxy for the increase in leisure).

${ }^{56}$ We probe a couple alternative explanations for these results. First, we have ignored the role of housing, which has both consumption and investment qualities. Lower-SES households are much less likely to have a mortgage prior to their lottery win, and given the stark differences we found by whether there was a mortgage in the pre-period, they are more likely to have acquired a mortgage and less likely to have paid one off (results not shown). To address this issue, we estimate regressions where we allow for both differential effects of lottery wins by pre-win income and differential effects of lottery wins by the pre-win presence of a mortgage (to hold constant any differential effects due to the latter). The results continue to show smaller earnings reductions and savings increases (Table 12, columns 2 and 4). Second, the exercise could be confounded by differential investment returns within the class of investments we use to construct our savings proxy or the failure to include alternative classes of investments that might be more prevalent among lower-SES households. As discussed in Appendix F, we do not find evidence consistent with these issues and conclude that they are unlikely to overturn the results. In sum, the available evidence indicates that lowerSES households appear to consume a higher fraction of their lottery winnings but with less of this spending dedicated to children's higher education

${ }^{57}$ However, it is not clear if the overall set of potential compliers (i.e., college ready children who do not go to college at baseline) is higher among higher or lower-SES households, given the offsetting fact that higher-SES children are both more college ready but also much more likely to enroll in college absent treatment.
} 
extensive and intensive margins (Table A46). Finally, lower-income households may inflate the price of college against alternative types of spending for which prices are more salient. There is evidence in the literature that the timing and complexity of financial aid causes a significant fraction of lower-income households to incorrectly perceive list tuition as the net cost of college (e.g., Dynarski and Scott-Clayton, 2006; Levine, 2014).

Overall, the results are not particularly consistent with financial constraints alone deterring investments in college that are then eased by the increased resources made available by a lottery win. Instead, the effects we detect are most consistent with spending on college increasing with resources in a fashion similar to normal goods.

\section{Relation to Prior Literature}

Lottery wins generate pure resource shocks that are salient to households and easily measured by the researcher. As presented in Table 1, \$100,000 more household income prior to college is associated with approximately 2.5 p.p. higher attendance at any college and 1.7 p.p. at four-year colleges (correlations that are likely upwardly biased by omitted factors such as college readiness and parental preferences), and our estimates explain one-quarter and one-third of these relationships, respectively. By tracing out causal effects across a wide range of resource shocks, for a wide range of household types, and across children of varying ages, our analysis provides useful context for interpreting estimates in the literature. For example, our results suggest that the wide range in prior estimates does not appear to be driven by the timing or amount of the shock or the population affected by the shock.

The estimated effects of household resources on college enrollment differ dramatically across studies, including across studies that exploit the same source of identifying variation (Table A48). Hilger (2016) finds that parental job loss reduces lifetime earnings by about $\$ 100,000$, but collegegoing by less than 0.5 p.p,, while Coelli (2011) and Pan and Ost (2014) find job loss effects of about 10 p.p. Bastian and Michelmore (2018) report no significant effect of the Earned Income Tax Credit (EITC) on initial college attendance, while Manoli and Turner (2018) find an effect of 1.3 p.p. per $\$ 1,000$ at the low income end of EITC eligibility (but an insignificant effect of 1.0 at the high end). Lovenheim (2011) finds that housing equity increases college attendance by 0.7 p.p. per $\$ 10,000$. That is, the effects documented in several studies are similar to or smaller than those in our analysis, while others exceed cross-sectional differences by an order of magnitude. 
Differentiating effects by household SES has been challenging in the literature due to the sources of variation used for identification. Analyses of the EITC are restricted to relatively small post-tax changes in income for lower-income households. Changes generated by job loss or housing equity are inherently tied to baseline income or housing wealth. The resulting findings with respect to heterogeneity are mixed. For example, Coelli (2011) and Hilger (2016) find smaller effects for lower-income households, while Lovenheim (2011) finds larger effects. Our findings over a wide range of resource shocks and households reveal that the effects are not highly concave and that the modest effects for lower-income households are not due to the magnitude of the change in resources they experience. Similarly, few papers that examine college-going differentiate effects by child age or grade, with most restricting attention to shocks that occur during high school. In cases where age is considered, the evidence is also mixed. For example, Manoli and Turner (2018) find significant effects if the EITC shock occurs in grade 12 but not 11; Bastian and Michelmore (2018) find effects of the EITC on high school and college graduation for exposure when the child is 13-18 years old but not earlier; and, Coelli (2011) finds effects if children are 16 or 17, but not 18. We are able to explicitly estimate effects by the timing of the win, revealing significant effects in each year prior to high school graduation.

The per-dollar relationships between income and college-going documented in this paper (and in the cross-section) are an order of magnitude smaller than the effects of changes in college price documented in much of the literature. ${ }^{58}$ Nonetheless, different-sized estimates derived from price and income changes are not contradictory for several reasons. First, large price effects are consistent with education being a normal good and do not necessarily imply that households are credit constrained (Carneiro and Heckman, 2002; Dynarski, 2003) ${ }^{59}$ Second, income effect studies generally examine the outcomes of all children affected by a household resource shock, while price effect estimates are often based on students who have applied to college or are eligible for meritbased grants. And third, if parents are not fully altruistic towards their children, then easing

\footnotetext{
${ }^{58}$ While some studies find modest changes in enrollment on the extensive margin, others find positive effects ranging from 1 to 5 p.p. per \$1,000 (Card and Lemieux, 2000; Dynarski, 2003; Abraham and Clark, 2006; Kane, 2007; Cohodes and Goodman, 2014; Castleman and Long, 2016; Denning, 2017; Bettinger et al., 2019).

${ }^{59}$ Nielsen, Sorensen, and Taber (2010) and Fack and Grenet (2015) find substantial price effects in France and Denmark which they argue are highly unlikely to stem from easing of credit constraints. Fack and Grenet (2015) note that if a significant fraction of households are credit constrained, that could actually attenuate the effect of modest changes in college price on enrollment as households could not respond.
} 
household income constraints will have more modest effects than reducing the prices faced by children.

\section{Conclusion}

This paper estimates the effect of household resources on college outcomes. It is the first study to exploit the universe of lottery wins in the U.S., and to leverage a wide range of resource shocks across a diverse population of households to examine changes in college-going. The analysis reveals several important results. Additional financial resources, including those at levels sufficient to cover college costs, have a modest effect on attendance. However, the effects are not highly concave and continue to increase for large resource shocks, reaching a high upper bound at win amounts far exceeding the cost of college. We also find that additional resources generate effects across each year prior to a student's high school graduation. The effects are concentrated at fouryear institutions and are not temporary, as we observe significant increases in enrollment for several years after high school graduation. Households that are most likely to face financial constraints are not more responsive than wealthier households, and there is no evidence that financial aid crowd-out is shaping this result. Finally, winning parents also decrease labor supply and increase housing consumption and savings, with some evidence that lower-income households have a higher marginal propensity to consume. These findings provide valuable context for interpreting existing studies of college access.

In the current policy environment, parental financial frictions alone do not appear to hinder college attendance for a significant fraction of households. This conclusion has several implications. First, the current set of subsidies available for higher education may be sufficient to overcome market failures stemming from financial frictions, at least at current tuition prices. However, to the extent that parents are not fully altruistic towards their children, our results may still be consistent with children facing binding borrowing constraints. Second, redistribution of income towards lower-SES households is unlikely to be sufficient to meaningfully close enrollment gaps, unless the transfers are far larger than what could conceivably operate through the tax system. Policies seeking to raise educational attainment by distributing resources likely need to incorporate features that address other potential obstacles in the transition to college (e.g., college and career counseling, remedial programs). Third, the results raise a new question of why increasing the resources of lower-SES households appears to be especially ineffective. Such 
households may have weaker preferences for post-secondary education, larger academic or informational constraints, different norms about who is responsible for financing higher education (Sallie Mae, 2015), and other financial priorities that inhibit their responsiveness. Future work should explore which channels operate and how policy can remedy these gaps.

\section{References}

Abraham, Katharine G, and Melissa A Clark. 2006. "Financial Aid and Students' College Decisions: Evidence from the District of Columbia Tuition Assistance Grant Program.” Journal of Human Resources 41(3): 578-610.

Acemoglu, Daron, and Jorn-Steffen Pischke. 2001. "Changes in the Wage Structure, Family Income, and Children's Education.” European Economic Review 45: 890-904.

Agarwal, Sumit, Chunlin Liu, and Nicholas S Souleles. 2007. "The Reaction of Consumer Spending and Debt to Tax Rebates: Evidence from Consumer Credit Data.” Journal of Political Economy 115(6): 986-1019.

Aizer, Anna, Shari Eli, Joseph Ferrie, and Adriana Lleras-Muney. 2016. “The Long-Run Impact of Cash Transfers to Poor Families.” American Economic Review 106(4): 935-971.

Akee, Randall K Q, William E Copeland, Gordon Keeler, Adrian Angold and E Jane Costello. 2010. "Parents' Incomes and Children's Outcomes: A Quasi-Experiment Using Transfer Payments from Casino Profits.” American Economic Journal: Applied Economics 2(1): 65-118. Almond, Douglas, Janet Currie, and Valentina Duque. 2018. "Childhood Circumstances and Adult Outcomes: Act II.” Journal of Economic Literature 56 (4): 1360-1446.

Alstadsæter, Annette. 2011. "Measuring the Consumption Value of Education.” CESifo Economic Studies 57(3): 458-479.

Alter, Molly, and Randall Reback. 2014. "True for Your School? How Changing Reputations Alter Demand for Selective U.S. Colleges.” Educational Evaluation and Policy Analysis 36 (3): 346370.

Ananat, Elizabeth Oltmans, Anna Gassman-Pines, Dania V Francis, and Christina M GibsonDavis. 2011. "Children Left Behind: The Effects of Statewide Job Loss on Student Achievement.” NBER Working Papers 17104.

Andersen, Steffen, and Kasper Meisner Nielsen. 2012. "Ability or Finances as Constraints on Entrepreneurship? Evidence from Survival Rates in a Natural Experiment." The Review of Financial Studies 25 (12): 3684-3710.

Ando, Albert, and Franco Modigliani. 1963. “The 'Life Cycle' Hypothesis of Saving: Aggregate Implications and Tests.” American Economic Review 53(1): 55-84.

Apouey, Benedicte, and Andrew E Clark. 2015. "Winning Big But Feeling No Better? The Effect of Lottery Prizes on Physical and Mental Health.” Health Economics 24(5): 516-538.

Arcidiacono, Peter. 2004. "Ability Sorting and the Returns to College Major." Journal of Econometrics 121: 343-375.

Auten, Gerald, and David Splinter. 2018. "Income Inequality in the United States: Using Tax Data to Measure Long-term Trends.” Working Paper.

Bailey, Martha J, and Susan M Dynarski. 2011. "Inequality in Postsecondary Education”. In G.J. Duncan and R.J. Murnane (eds.), Whither Opportunity? Rising Inequality, Schools, and Children's Life Chances. Russell Sage: New York, New York. 
Bastian, Jacob, and Katherine Michelmore. 2018. "The Long-Term Impact of the Earned Income Tax Credit on Children's Education and Employment Outcomes.” Journal of Labor Economics 36(4): 1127-1163.

Belley, Philippe, and Lance Lochner. 2007. “The Changing Role of Family Income and Ability in Determining Educational Achievement.” Journal of Human Capital 1(1): 37-89.

Bettinger, Eric, Oded Gurantz, Laura Kawano, Bruce Sacerdote, and Michael Stevens. 2019. “The Long-Run Impacts of Financial Aid: Evidence from California's Cal Grant.” American Economic Journal: Economic Policy 11(1): 64-94.

Bleakley, Hoyt, and Joseph P Ferrie. 2016. "Shocking Behavior: Random Wealth in Antebellum Georgia and Human Capital Across Generations.” Quarterly Journal of Economics 131(3): 1455-1495.

Blau, David M. 1999. “The Effect of Income on Child Development.” Review of Economics and Statistics 81(2): 261-276.

Bostic, Raphael, Stuart Gabriel, and Gary Painter. 2009. "Housing Wealth, Financial Wealth, and Consumption: New Evidence from Micro Data.” Regional Science and Urban Economics 39: 79-89.

Bratberg, Espen, Øivind Anti Nilsen, and Kjell Vaage. 2008. "Job losses and child outcomes.” Labour Economics 15: 591-603.

Bricker, Jesse, Alice Henriques, Jacob Krimmel, and John Sabelhaus. 2016. "Measuring Income and Wealth at the Top Using Administrative and Survey Data." Brookings Papers on Economic Activity Spring: 261-331.

Brown, Meta, John Karl Scholz, and Ananth Seshadri. 2012. “A New Test of Borrowing Constraints for Education.” Review of Economic Studies 79(2): 511-538.

Cameron, Stephen V, and James J Heckman. 1998. "Life Cycle Schooling and Dynamic Selection Bias: Models and Evidence for Five Cohorts of American Males.” Journal of Political Economy 106(2): 262-333.

Cameron, Stephen V, and James J Heckman. 2001. “The Dynamics Of Educational Attainment For Black Hispanic, And White Males.” Journal of Political Economy 109(3): 455-499.

Cameron, Stephen V, and Christopher Taber. 2004. "Estimation of Educational Borrowing Constraints Using Returns to Schooling.” Journal of Political Economy 112(1): 132-182.

Card, David, and Thomas Lemieux. 2000. "Dropout and Enrollment Trends in the Post-War Period: What Went Wrong in the 1970s?.” NBER Working Papers 7658.

Carneiro, Pedro, and James Heckman. 2002. "The Evidence on Credit Constraints in PostSecondary Schooling.” The Economic Journal 112: 705-734.

Carneiro, Pedro, Katrine Løken, and Kjell Salvanes. 2015. “A Flying Start? Maternity Leave Benefits and Long-Run Outcomes of Children.” Journal of Political Economy 123 (2): 365-412. Castleman, Ben, and Bridget Terry Long. 2016. "Looking Beyond Enrollment: The Causal Effect of Need-Based Grants on College Access, Persistence, and Graduation.” Journal of Labor Economics 34(4): 1023-1073.

Caucutt, Elizabeth M, and Lance Lochner. 2020. "Early and Late Human Capital Investments, Borrowing Constraints, and the Family.” Journal of Political Economy 128 (3): 1065-1147.

Cesarini, David, Erik Lindqvist, Matthew J Notowidigdo, and Robert Ostling. 2017. "The Effect of Wealth on Individual and Household Labor Supply: Evidence from Swedish Lotteries.” American Economic Review 107(12): 3917-1946. 
Cesarini, David, Erik Lindqvist, Robert Ostling, and Bjorn Wallace. 2016. "Wealth, Health, and Child Development: Evidence from Administrative Data on Swedish Lottery Players." Quarterly Journal of Economics 131(3): 1455-1495.

Chetty, Raj, Nathaniel Hendren, and Lawrence F Katz. 2016. "The Effects of Exposure to Better Neighborhoods on Children: New Evidence from the Moving to Opportunity Experiment.” American Economic Review 106(4): 855-902.

Chetty, Raj, and Nathaniel Hendren. 2018. "The Impacts of Neighborhoods on Intergenerational Mobility II: County-Level Estimates.” The Quarterly Journal of Economics 133(3): 1163-1228.

Chiappori, Pierre-André, Murat Iyigun, and Yoram Weiss. 2009. "Investment in Schooling and the Marriage Market.” American Economic Review 99(5): 1689-1713.

Coelli, Michael B. 2011. "Parental Job Loss and the Education Enrollment of Youth." Labour Economics 18: 25-35.

Cohodes, Sarah R, and Joshua S Goodman. 2014. "Merit Aid, College Quality, and College Completion: Massachusetts' Adams Scholarship as an In-Kind Subsidy.” American Economic Journal: Applied Economics 6(4): 251-285.

Cowan, Benjamin. 2016. "Testing for Educational Credit Constraints Using Heterogeneity in Individual Time Preferences.” Journal of Labor Economics 34(2): 363-402.

Crook, Jonathan. 1996. “Credit Constraints and US Households.” Applied Financial Economics 6: 477-485.

Crosier, David, Ralitsa Donkova, Anna Horvath, Daniela Kocanova, Anita Kremo, Teodora Parveva, and Jari Riiheläinen. 2018. "Opening Higher Education to a Diverse Student Population.” The European Higher Education Area in 2018. European Commission: 153-214.

Dahl, Gordon B, and Lance Lochner. 2012. "The Impact of Family Income on Child Achievement: Evidence from the Earned Income Tax Credit.” American Economic Review 102(5): 1927-1956. Deming, David. 2009. "Early Childhood Intervention and Life-Cycle Skill Development: Evidence from Head Start.” American Economic Journal: Applied Economics 1 (3): 111-134.

Denning, Jeffrey T. 2017. "College on the Cheap: Consequences of Community College Tuition Reductions.” American Economic Journal: Economic Policy 9(2): 155-188.

Dustmann, Christian, and Uta Schönberg. 2012. "Expansions in Maternity Leave Coverage and Children's Long-Term Outcomes.” American Economic Journal: Applied Economics 4 (3): 190224.

Dynarski, Susan. 2003. "Does Aid Matter? Measuring the Effect of Student Aid on College Attendance and Completion.” American Economic Review 93(1): 279-288.

Dynarski, Susan. 2004. “Tax Policy and Education Policy: Coordination or Collision?” Tax Policy and the Economy 18: 81-116.

Dynarski, Susan, and Judith Scott-Clayton. 2006. "The Cost of Complexity in Federal Student Aid: Lessons from Optimal Tax Theory and Behavioral Economics.” National Tax Journal 59(2): 319-356.

Eckstein, Zvi, and Kenneth I Wolpin. 1999. "Why Youths Drop Out of High School: The Impact of Preferences, Opportunities, and Abilities.” Econometrica 67(6): 1295-1339.

Fack, Gabrielle, and Julien Grenet. 2015. "Improving College Access and Success for LowIncome Students: Evidence from a Large Need-Based Grant Program.” American Economic Journal: Applied Economics 7(2): 1-34.

Federal Reserve Board. 2017. "Report on the Economic Well-Being of U.S. Households in 2016." https://www.federalreserve.gov/publications/files/2016-report-economic-well-being-ushouseholds-201705.pdf 
Friedman, Milton. 1957. “The Permanent Income Hypothesis.” In A Theory of the Consumption Function, Princeton University Press, 20-37.

Gong, Yifan, Lance Lochner, Ralph Stinebrickner, and Todd R Stinebrickner. 2019. “The Consumption Value of College.” NBER Working Papers 26335.

Glied, Sherry, and Adriana Lleras-Muney. 2008. "Health Inequality, Education and Medical Innovation." Demography 45(3): 741-761.

Hamermesh, Daniel S. 1999. "Changing Inequality in Markets for Workplace Amenities.” The Quarterly Journal of Economics 114(4): 1085-1123.

Hankins, Scott, Mark Hoekstra, and Paige Skiba. 2011. "The Ticket to Easy Street? The Financial Consequences of Winning the Lottery.” Review of Economics and Statistics 93: 961-969.

Hanushek, Eric A, Charles Ka Yui Leung, and Kuzey Yilmaz. 2014. "Borrowing Constraints, College Aid, and Intergenerational Mobility." Journal of Human Capital 8(1): 1-41.

Heckman, James, Rodrigo Pinto, and Peter Savelyev. 2013. "Understanding the Mechanisms through Which an Influential Early Childhood Program Boosted Adult Outcomes.” American Economic Review 103 (6): 2052-2086.

Hilger, Nathaniel. 2016. "Parental Job Loss and Children's Long-Term Outcomes: Evidence From 7 Million Fathers' Layoffs.” American Economic Journal: Applied Economics 8(3): 247-283.

Holtz-Eakin, Douglas, David Joulfaian and Harvey S Rosen. 1994. "Entrepreneurial Decisions and Liquidity Constraints.” RAND Journal of Economics 25(2): 334-347.

Imbens, Guido W, Donald B Rubin, and Bruce I Sacerdote. 2001. "Estimating the Effect of Unearned Income on Labor Earnings, Savings, and Consumption: Evidence from a Survey of Lottery Players.” American Economic Review 91(4): 778-794.

Jacob, Brian, Brian McCall, and Kevin Stange. 2018. “College as Country Club: Do Colleges Cater to Students’ Preferences for Consumption?” Journal of Labor Economics 36(2): 309-348. Jacob, Brian, and Lars Lefgren. 2007. "What Do Parents Value in Education? An Empirical Investigation of Parents’ Revealed Preferences for Teachers.” Quarterly Journal of Economics 122(4): 1603-1637.

Jappelli, Tullio. 1990. “Who is Credit Constrained in the U. S. Economy?” The Quarterly Journal of Economics 105(1): 219-234.

Japelli, Tullio, Jorn-Steffen Pischke, and Nicholas Souleles. 1998. "Testing for Liquidity Constraints in Euler Equations with Complementary Data Sources.” The Review of Economics and Statistics 80(2): 251-262.

Johnson, David, S, Jonathan A Parker, and Nicholas S Souleles. 2006. "Household Expenditure and the Income Tax Rebates of 2001.” American Economic Review 96 (5): 1589-1610.

Johnson, Michael. 2013. "Borrowing Constraints, College Enrollment, and Delayed Entry." Journal of Labor Economics 31(4): 669-725.

Kane, Thomas J. 2007. "Evaluating the Impact of the D.C. Tuition Assistance Grant Program.” Journal of Human Resources 42(3): 555-582.

Keane, Michael P, and Kenneth I Wolpin. 1997. “The Career Decisions of Young Men.” Journal of Political Economy 105(3): 473-522.

Keane, Michael P, and Kenneth I Wolpin. 2000. “Eliminating Race Differences in School Attainment and Labor Market Success.” Journal of Labor Economics 18(4): 614-652.

Keane, Michael P, and Kenneth I Wolpin. 2001. "The Effect of Parental Transfers and Borrowing Constraints on Educational Attainment.” International Economic Review 42(4): 1051-1103.

Kearney, Melissa S. 2005. "State Lotteries and Consumer Behavior." Journal of Public Economics 89: 2269-2299. 
Kodde, David A, and Jozef M Ritzen. 1984. "Integrating Consumption and Investment Motives in a Neoclassical Model of Demand for Education.” Kyklos 37(4): 598-605.

Kuhn, Peter, Peter Kooreman, Adriaan Soetevent, and Arie Kapteyn. 2011. "The Effects of Lottery Prizes on Winners and Their Neighbors: Evidence from the Dutch Postcode Lottery.” American Economic Review 101(5): 2226-2247.

Lafortune, Jeanne. 2013. "Making Yourself Attractive: Pre-Marital Investments and the Returns to Education in the Marriage Market.” American Economic Journal: Applied Economics 5(2): 151-178.

Lazear, Edward. 1977. “Education: Consumption or Production?” Journal of Political Economy 85(3): 569-598.

Levine, Phillip. 2014. “Transparency in College Costs.” Economic Studies Working Paper. Brookings Institution.

Lindahl, Mikael. 2005. "Estimating the Effect of Income on Health and Mortality Using Lottery Prizes as an Exogenous Source of Variation in Income.” Journal of Human Resources 40(1): 144-168.

Lindh, Thomas, and Henry Ohlsson. 1996. "Self-Employment and Windfall Gains: Evidence from the Swedish Lottery.” Economic Journal, 106(439): 1515-1526.

Lochner, Lance J, and Alexander Monge-Naranjo. 2011. "The Nature of Credit Constraints and Human Capital.” American Economic Review 101(6): 2487-2529.

Loken, Katrine. 2010. "Family Income and Children's Education: Using the Norwegian Oil Boom as a Natural Experiment.” Labour Economics 17(1):118-129.

Loken, Katrine V, Magne Mogstad, and Matthew Wiswall. 2012. "What Linear Estimators Miss: The Effects of Family Income on Child Outcomes." American Economic Journal: Applied Economics 4(2): 1-35.

Lovenheim, Michael F. 2011. "The Effect of Liquid Housing Wealth on College Enrollment." Journal of Labor Economics 29(4): 741-771.

Lovenheim, Michael F, and C Lockwood Reynolds. 2013. "The Effect of Housing Wealth on College Choice: Evidence from the Housing Boom.” Journal of Human Resources 48(1): 1-35.

Manoli, Day, and Nicholas Turner. 2018. "Cash-on-Hand and College Enrollment: Evidence from Population Tax Data and the Earned Income Tax Credit." American Economic Journal: Economic Policy 10(2): 242-271.

Marx, Benjamin, and Lesley Turner. 2018. "Borrowing Trouble? Human Capital Investment with Opt-In Costs and Implications for the Effectiveness of Grant Aid.” American Economic Journal: Applied Economics 10(2): 163-201.

Maurin, Eric. 2002. "The Impact of Parental Income on Early Schooling Transitions: A ReExamination Using Data over Three Generations.” Journal of Public Economics 85(3): 301-332. Milligan, Kevin, and Mark Stabile. 2011. "Do Child Tax Benefits Affect the Well-being of Children? Evidence from Canadian Child Benefit Expansions.” American Economic Journal: Economic Policy 3(3): 175-205.

Nielsen, Helena Skyt, Torben Sørensen, and Christopher Taber. 2010. "Estimating the Effect of Student Aid on College Enrollment: Evidence from a Government Grant Policy Reform.” American Economic Journal: Economic Policy 2: 185-215.

OECD. 2017. Education at a Glance 2017: OECD Indicators. OECD Publishing, Paris. http://dx.doi.org/10.1787/eag-2017-en.

Oreopoulos, Philip, Marianne Page, and Ann Huff Stevens. 2008. "The Intergenerational Effects of Worker Displacement.” Journal of Labor Economics 26(3): 455-483. 
Oreopoulos, Philip, and Kjell G Salvanes. 2011. "Priceless: The Nonpecuniary Benefits of Schooling.” Journal of Economic Perspectives (25)1: 159-184.

Orr, Dominic, Alex Usher, Cezar Haj, Graeme Atherton, and Irina Geanta. 2017. "Study on the Impact of Admission Systems on Higher Education Outcomes." European Commission Comparative Report.

Oster, Emily. 2004. “Are All Lotteries Regressive? Evidence from the Powerball.” National Tax Journal 57 (2): 179-187.

Page, Lindsay C, and Judith Scott-Clayton. 2016. "Improving College Access in the United States: Barriers and Policy Responses." Economics of Education Review 51: 4-22.

Pallais, Amanda, and Sarah Turner. 2006. Opportunities for Low-Income Students at Top Colleges and Universities: Policy Initiatives and the Distribution of Students. National Tax Journal 59 (2): 357-386.

Pan, Weixiang, and Ben Ost. 2014. "The Impact of Parental Layoff on Higher Education Investment." Economics of Education Review 42: 53-63.

Parker, Jonathan. 1999. "The Reaction of Household Consumption to Predictable Changes in Social Security Taxes.” American Economic Review 89(4): 959-973.

Parker, Jonathan, Nicholas Souleles, David Johnson, and Robert McClelland. 2013. "Consumer Spending and the Economic Stimulus Payments of 2008." American Economic Review, 103(6): 2530-2553.

Pierce, Brooks. 2001. “Compensation Inequality.” The Quarterly Journal of Economics 116(4): 1493-1525.

Powdthavee, Nattavudh, and Andrew J Oswald. 2014. "Does Money Make People Right-Wing and Inegalitarian? A Longitudinal Study of Lottery Winners.” IZA Discussion Paper No. 7934.

Rege, Mari, Kjetil Telle, and Mark Votruba. 2011. "Parental Job Loss and Children's School Performance.” The Review of Economic Studies 78(4): 1462-1489.

Saez, Emmanuel, and Gabriel Zucman. 2016. "Wealth Inequality in the United States since 1913: Evidence from Capitalized Income Tax Data.” The Quarterly Journal of Economics 131(2): 519578.

Sallie Mae. 2015. “How America Pays for College.” Sallie Mae’s National Study of College Students and Parents.

Schaafsma, Joseph. 1976. "The Consumption and Investment Aspects of the Demand for Education.” Journal of Human Resources 11(2): 233-242.

Shapiro, Matthew D, and Joel Slemrod. 1995. "Consumer Response to the Timing of Income: Evidence from a Change in Tax Withholding.” American Economic Review 85(1): 274-283.

Shapiro, Matthew, D, and Joel Slemrod. 2003. "Consumer Response to Tax Rebates." American Economic Review 93(1): 381-396.

Shea, John. 2000. “Does Parents’ Money Matter?” Journal of Public Economics 77: 155-184.

Silles, Mary. 2009. "The Causal Effect of Education on Health: Evidence from the United Kingdom.” Economics of Education Review 28(1): 122-128.

Souleles, Nicholas. 1999. "The Response of Household Consumption to Income Tax Refunds." American Economic Review 89(4): 947-958.

Stinebrickner Ralph, and Todd Stinebrickner. 2008. "The Effect of Credit Constraints on the College Drop-Out Decision: A Direct Approach Using a New Panel Study.” American Economic Review 98(5): 2163-2184.

Taylor, Mark P. 2001. Self-Employment and Windfall Gains in Britain: Evidence from Panel Data.” Economica 68: 539-565. 
Weinberg, Bruce A. 2001. "An Incentive Model of the Effect of Parental Income on Children.” Journal of Political Economy 109(2): 266-280. 
Figure 1: College Attendance Within One Year of High School Graduation by the Amount and Timing of the Lottery Win

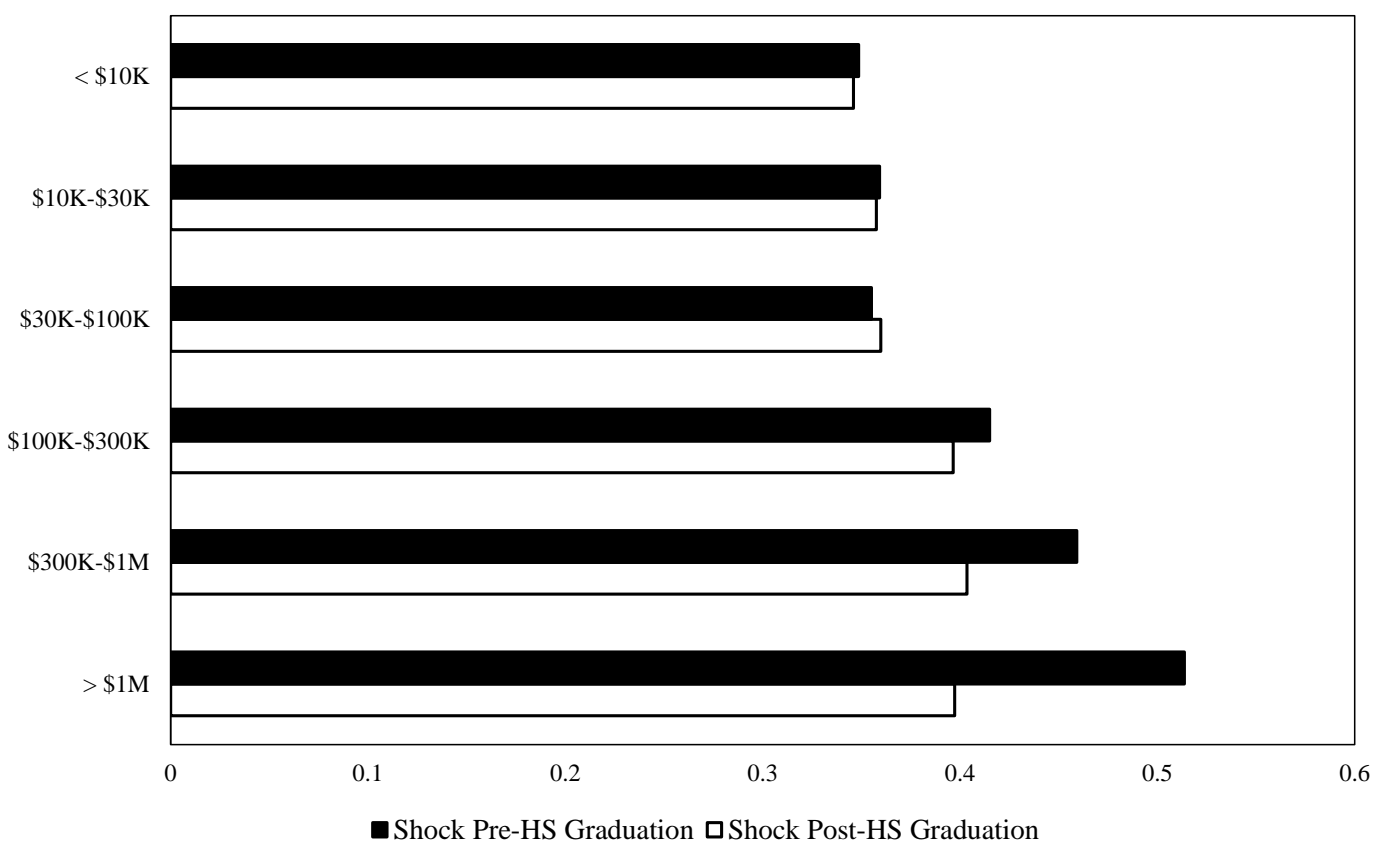

Note: This figure presents the average rate of attending any college for children who graduate before and after their parent wins a lottery. Attendance is measured in the year of expected high school graduation and rates are adjusted for cohort fixed effects. Win sizes are adjusted to 2010 dollars and are classified according to six cutoffs: $\$ 10,000, \$ 30,000, \$ 100,000, \$ 300,000$, and $\$ 1,000,000$. 
Figure 2: Four-Year College Attendance: LOWESS Plot of Lottery Win Effects

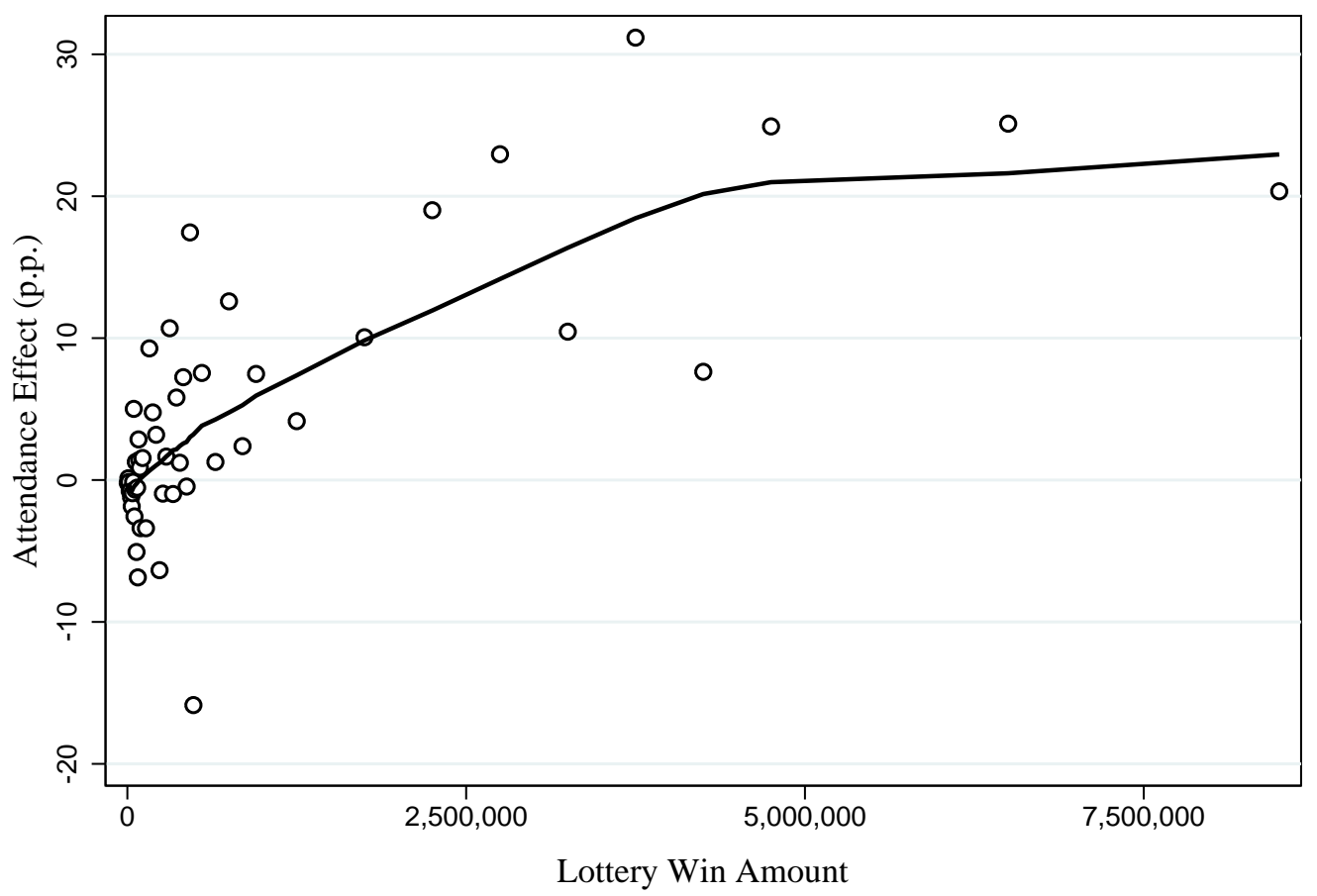

Note: This figure presents a LOWESS plot fitted to the effects of lottery wins on four-year college attendance in the year of high school graduation. The effects are in percentage points and are plotted for increments of $\$ 5,000$ up to $\$ 100,000, \$ 25,000$ up to $\$ 500,000, \$ 100,000$ up to $\$ 1,000,000, \$ 500,000$ up to $\$ 5,000,000$, and $\$ 2,500,000$ up to $\$ 10,000,000$. Effect sizes are estimated relative to small wins of less than $\$ 1,000$. The estimates account for state-by-year of win fixed effects, cohort fixed effects, parent wages, adjusted gross income, filing status (joint or single), gender, citizenship, missing returns, mortgage payments, Social Security income, self-employment income, household number of children, and child gender, citizenship, and an indicator for Social Security birth match to parent, with the omitted variables being a large win and one of the year effects. All student and parent controls are based on pre-win measures. Smoothing is based on a bandwidth of 0.8 . 
Figure 3a: Estimated Effects on Four-Year Attendance for Lottery Wins $>\$ 100,000$ by Timing of Win Relative to High School Graduation

Percentage points

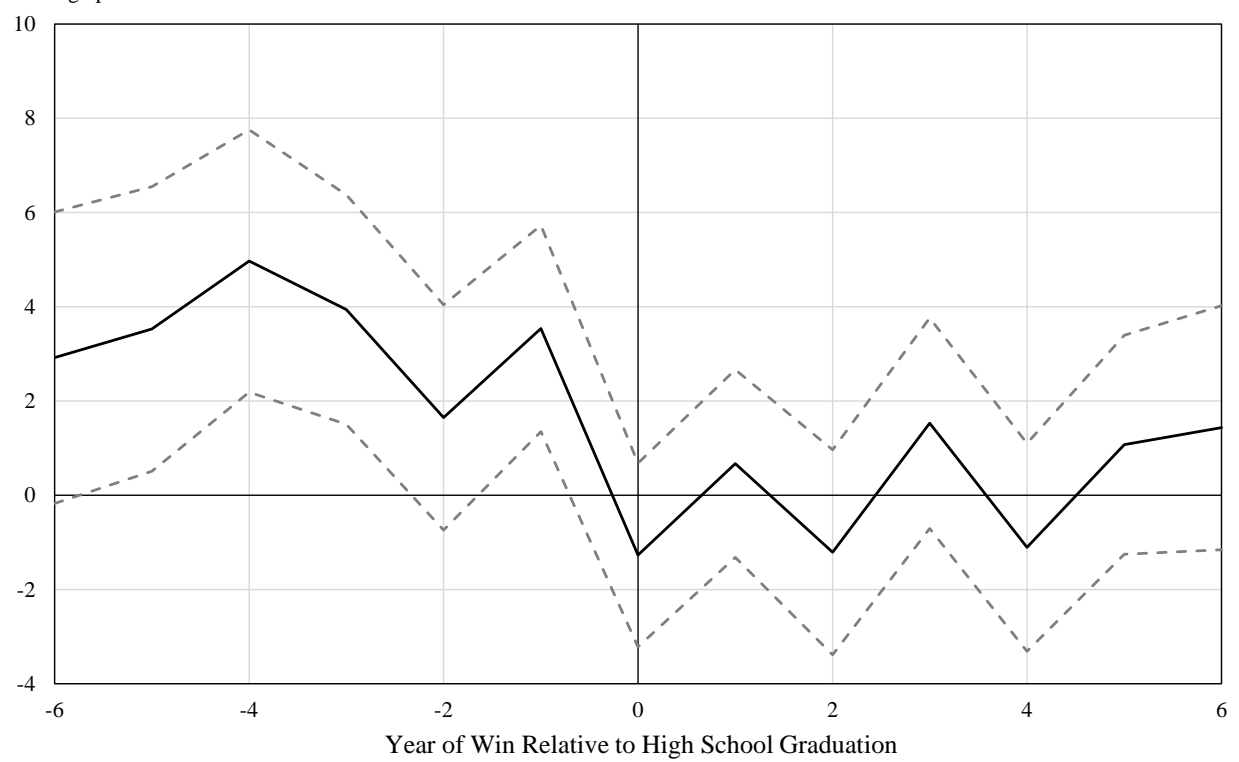

Figure 3b: Estimated Effects on Four-Year Attendance for Lottery Wins $>\$ 300,000$ by Timing of Win Relative to High School Graduation

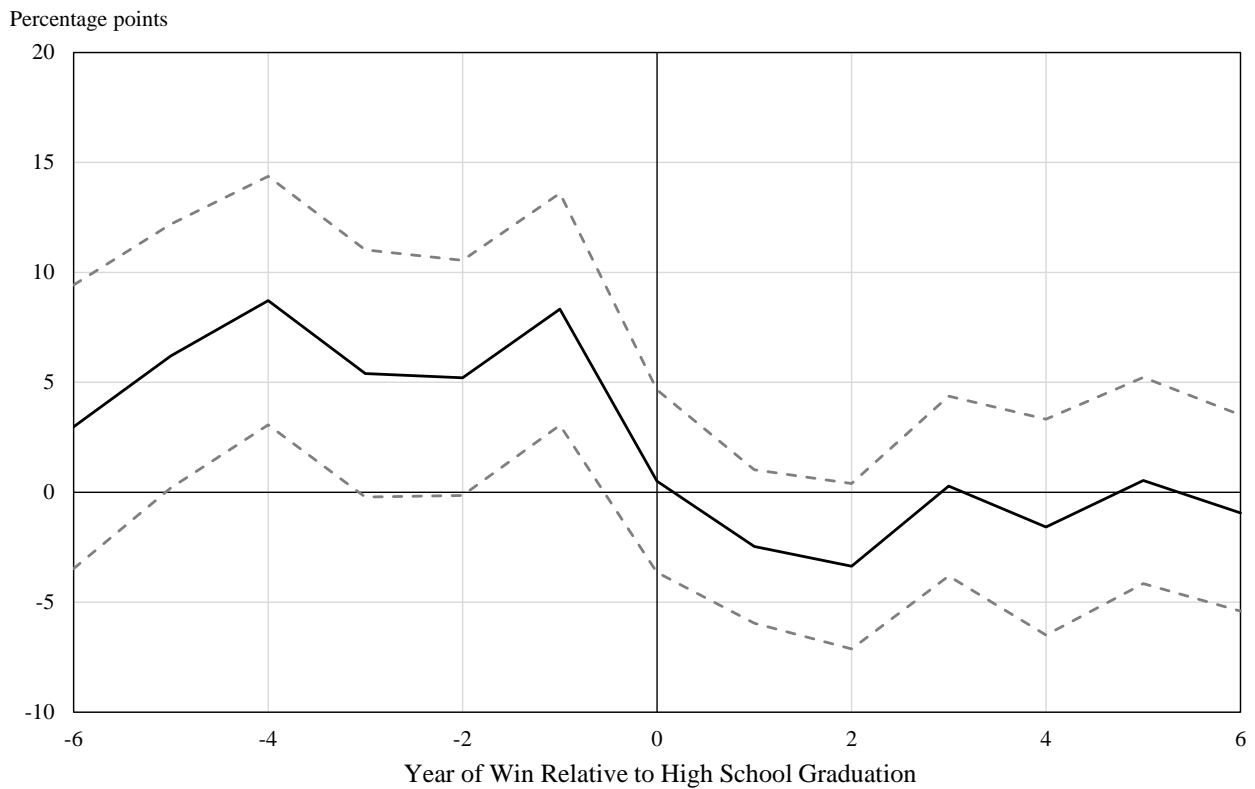

Note: This figure presents the estimated percentage point difference in four-year college attendance for children whose parents won a large lottery relative to those whose parents won a small lottery in each year before and after the expected year of high school graduation. The estimates account for state-by-year of win fixed effects, cohort fixed effects, parent wages, adjusted gross income, filing status (joint or single), gender, citizenship, missing returns, mortgage payments, Social Security income, self-employment income, household number of children, and child gender, citizenship, and an indicator for Social Security birth match to parent, with the omitted variables being a large win and one of the year effects. All student and parent controls are based on pre-win measures. In the top figure, large wins are defined as those exceeding $\$ 100,000$, while small lotteries are those of less than $\$ 100,000$ (which average $\$ 3,294$ ). In the bottom figure, large wins are those exceeding $\$ 300,000$ and wins between $\$ 100,000$ and $\$ 300,000$ are excluded. Dashed lines depict the 95 percent confidence interval. 


\section{Figure 4: Parental Earnings Before and After Lottery Wins}
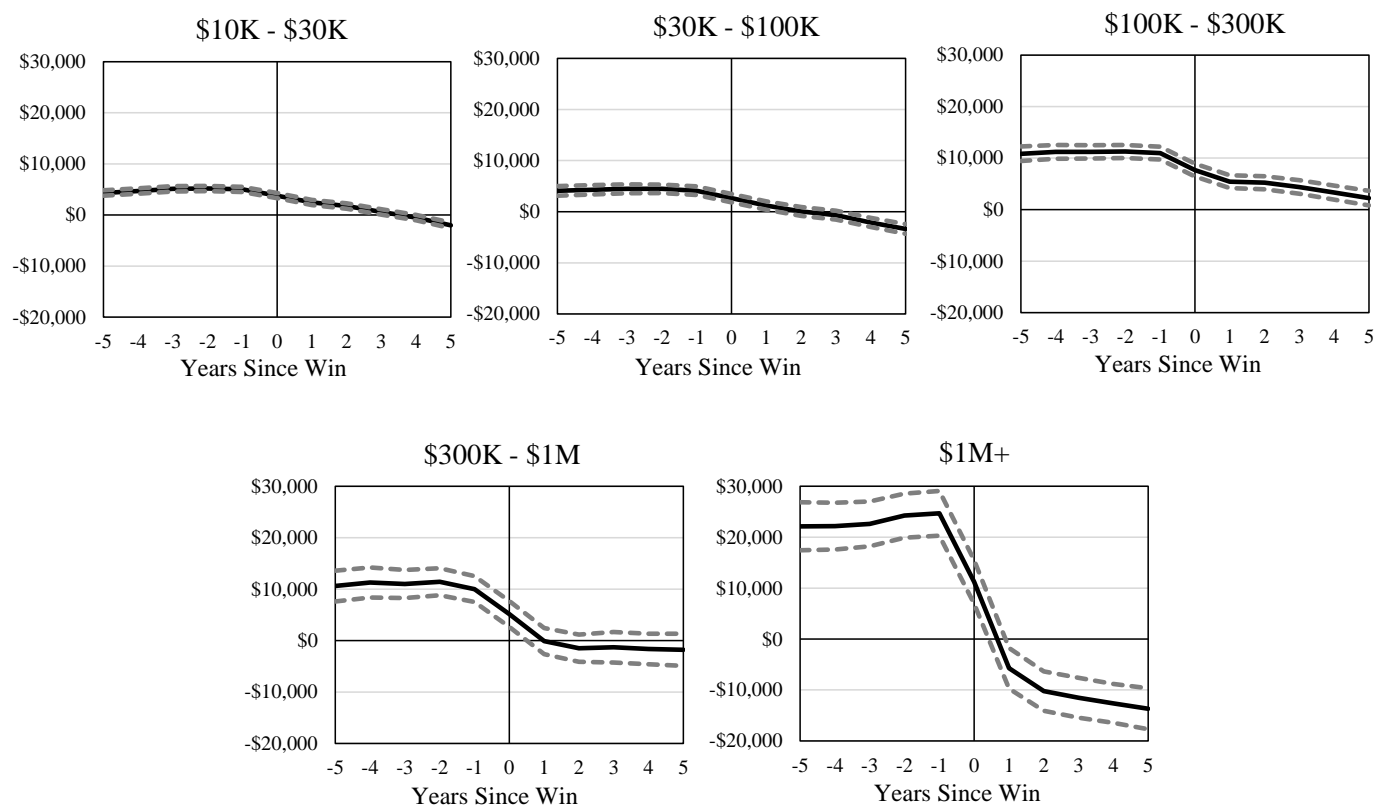

Note: These figures present changes in parental earnings in the years before and after a lottery win relative to households with wins of less than $\$ 10,000$. Estimates are presented for each of five larger win groups, corresponding to cutoffs of $\$ 30,000, \$ 100,000$, $\$ 300,000$, and $\$ 1,000,000$ or more. Earnings and win sizes are adjusted to 2010 dollars. Year 0 is the year during which the win occurred and thus is likely to represent partial treatment. 
Table 1: Cross-Sectional Relationship Between College Enrollment and Household Income

\begin{tabular}{|c|c|c|c|c|c|}
\hline \multirow[b]{3}{*}{ Four-Year College } & (1) & (2) & (3) & (4) & (5) \\
\hline & \multicolumn{5}{|c|}{ Average Annual Income } \\
\hline & $\$ 0-25 \mathrm{k}$ & $\$ 0-50 \mathrm{k}$ & $\$ 0-100 \mathrm{k}$ & $\$ 0-150 \mathrm{k}$ & $\$ 0-200 \mathrm{k}$ \\
\hline \multirow[t]{2}{*}{ Total Household Income Age 0-18 (\$100k) } & $0.0123^{* * *}$ & $0.0153^{* * *}$ & $0.0166^{* * *}$ & $0.0172^{* * *}$ & $0.0168^{* * *}$ \\
\hline & $(0.0006)$ & $(0.0002)$ & $(0.0001)$ & $(0.0001)$ & $(0.0001)$ \\
\hline Mean Dep & 0.107 & 0.136 & 0.183 & 0.205 & 0.211 \\
\hline \multirow[t]{3}{*}{ Observations } & 377,386 & 840,957 & $1,316,239$ & $1,446,270$ & $1,474,902$ \\
\hline & (6) & (7) & $(8)$ & (9) & $(10)$ \\
\hline & \multicolumn{5}{|c|}{ Average Annual Income } \\
\hline Any College & $\$ 0-25 \mathrm{k}$ & $\$ 0-50 \mathrm{k}$ & $\$ 0-100 \mathrm{k}$ & $\$ 0-150 \mathrm{k}$ & $\$ 0-200 \mathrm{k}$ \\
\hline \multirow[t]{2}{*}{ Total Household Income Age 0-18 (\$100k) } & $0.0206^{* * *}$ & $0.0251^{* * *}$ & $0.0259^{* * *}$ & $0.0242^{* * *}$ & $0.0225^{* * *}$ \\
\hline & $(0.0007)$ & $(0.0002)$ & $(0.0001)$ & $(0.0001)$ & $(0.0001)$ \\
\hline Mean Dep & 0.185 & 0.233 & 0.307 & 0.334 & 0.341 \\
\hline Observations & 377,386 & 840,957 & $1,316,239$ & $1,446,270$ & $1,474,902$ \\
\hline
\end{tabular}

Note: This table presents the cross-sectional relationship between college attendance and household income during childhood in 2010 dollars, over increasing ranges of average household income. Total household income during childhood (in hundreds of thousands of dollars) is computed by taking the average of all available years of income from tax returns before the lottery win and multiplying by 18 . The sample is restricted to households with at least five years of income data. Estimates are differentiated for households with average annual incomes of less than $\$ 25,000, \$ 50,000, \$ 100,000, \$ 150,000$, and $\$ 200,000$. The top panel presents the relationship for four-year college attendance and the bottom panel presents the relationship for any college attendance. Errors are clustered at the household level. The symbols *,**, and *** represent statistical significance at 10,5 , and 1 percent respectively. 
Table 2: Summary Statistics: Lottery Wins and College Attendance

\begin{tabular}{lccccc}
\hline \hline Win Size Distribution & $\begin{array}{c}\text { Number } \\
\text { Children }\end{array}$ & $\begin{array}{c}\text { Median } \\
\text { Win }\end{array}$ & $\begin{array}{c}\text { Mean } \\
\text { Win }\end{array}$ & $\begin{array}{c}\text { Mean } \\
\text { After Tax }\end{array}$ & $\begin{array}{c}\text { Subsequent } \\
\text { Win }>10 k\end{array}$ \\
\hline Income Shock 600 to 10,000 & $1,365,498$ & 1,189 & 2,047 & 1,671 & 0.03 \\
Income Shock 10,000 to 30,000 & 62,239 & 11,900 & 15,252 & 12,034 & 0.04 \\
Income Shock 30,000 to 100,000 & 19,608 & 50,000 & 52,152 & 40,319 & 0.04 \\
Income Shock 100,000 to 300,000 & 10,318 & 153,421 & 169,383 & 121,551 & 0.04 \\
Income Shock 300,000 to 1,000,000 & 2,301 & 525,000 & 568,269 & 381,548 & 0.04 \\
Income Shock 1,000,000 or more & 1,298 & $2,082,322$ & $7,704,497$ & $4,953,009$ & 0.03 \\
\hline Cumulative College Attendance & Year 0 & Year 1 & Year 2 & Year 3 & Year 4 \\
\hline Any College & 0.35 & 0.45 & 0.50 & 0.53 & 0.55 \\
Four-Year College & 0.22 & 0.27 & 0.30 & 0.33 & 0.35 \\
Two-Year College & 0.14 & 0.23 & 0.28 & 0.31 & 0.34 \\
\hline \hline
\end{tabular}

Note: This table presents summary statistics for the lottery wins that affect each child, as well as the timing of their initial college attendance. Column 1 of the top panel presents the number of children affected by wins in each of six size ranges: $\$ 600$ to $\$ 9,999, \$ 10,000$ to $\$ 29,999, \$ 30,000$ to $\$ 99,999, \$ 100,000$ to $\$ 299,999, \$ 300,000$ to $\$ 999,999$, and $\$ 1,000,000$ or more. Columns 2 and 3 present the median and mean of these wins. Column 4 presents the mean lottery win amount after deducting income taxes, which are estimated using each household's income level in the year prior to the win. Win range categories in Column 4 are based on pre-tax amounts. Column 5 presents the fraction of children whose parents experience total lottery wins exceeding $\$ 10,000$ in the four years after the initial win. The bottom panel presents the cumulative fraction of children in the sample who have attended college by each year after the expected year of high school graduation. Cumulative attendance is presented for any college, four-year college, and two-year college. 
Table 3: Lottery Wins and Covariate Balance

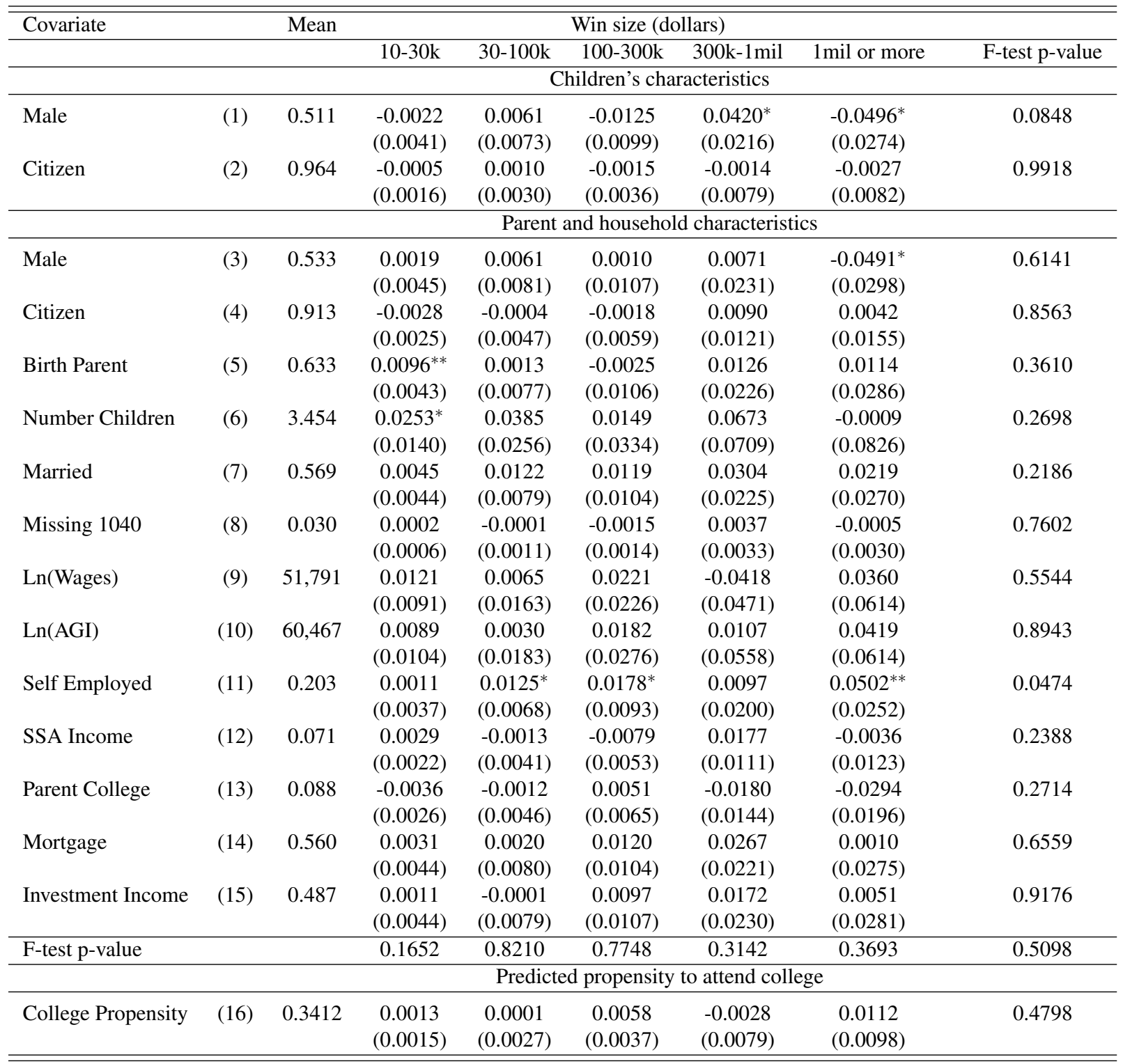

Note: This table applies the empirical design to child, parent, and household characteristics to test for balance. Each row represents a separate variable. The specification includes state-by-year of win and student cohort fixed effects. Household characteristics are based on the three years prior to the lottery win. All characteristics are binary variables except number of children, log income, log wages, and college propensity. Whether an individual is married is derived from filing status, number of children is derived from children ever claimed as a dependent, gender and citizenship status are based on Social Security records, parental college enrollment is based on the Form 1098-T, and wages, adjusted gross income, Social Security Income, having a mortgage, and investment income are derived from the Form 1040 and third-party mandatory reporting forms. Column 1 presents wage and income means in levels for ease of interpretation. F-tests of joint significance for each covariate are presented at the bottom of every column and across win sizes at the end of every row. An F-test for the joint significance of all covariates across all win sizes is presented at the bottom of the last column of the second panel. The measure of the propensity to attend college is the predicted probability that a student attends college based on coefficients derived from a cross-sectional regression of attendance on all 15 household characteristics for children too old to be affected by the lottery win. The symbols $*, * *$, and $* * *$ represent statistical significance at 10,5 , and 1 percent respectively. 
Table 4: College Attendance in the Year of High School Graduation

\begin{tabular}{llccccc}
\hline \hline & \multicolumn{1}{c}{$\begin{array}{c}(1) \\
\text { Any College }\end{array}$} & \multicolumn{1}{c}{$\begin{array}{c}(3) \\
\text { Four-Year College }\end{array}$} & \multicolumn{2}{c}{$\begin{array}{c}(5) \\
\text { Two-Year College }\end{array}$} \\
\hline Win 10-30k Pre-HS Grad & -0.0022 & -0.0033 & -0.0016 & -0.0025 & -0.0023 & -0.0026 \\
& $(0.0041)$ & $(0.0038)$ & $(0.0035)$ & $(0.0034)$ & $(0.0030)$ & $(0.0029)$ \\
Win 30-100k Pre-HS Grad & -0.0101 & -0.0100 & -0.0075 & -0.0075 & -0.0043 & -0.0042 \\
& $(0.0073)$ & $(0.0067)$ & $(0.0062)$ & $(0.0059)$ & $(0.0054)$ & $(0.0053)$ \\
& $0.0169^{*}$ & 0.0109 & $0.0188^{* *}$ & $0.0143^{*}$ & -0.0025 & -0.0044 \\
Win 100-300k Pre-HS Grad & $(0.0101)$ & $(0.0093)$ & $(0.0091)$ & $(0.0086)$ & $(0.0074)$ & $(0.0072)$ \\
& $0.0559^{* * *}$ & $0.0590^{* * *}$ & $0.0539^{* * *}$ & $0.0566^{* * *}$ & 0.0076 & 0.0082 \\
Win 300k-1.0m Pre-HS Grad & $(0.0217)$ & $(0.0200)$ & $(0.0195)$ & $(0.0185)$ & $(0.0160)$ & $(0.0159)$ \\
& $0.1039^{* * *}$ & $0.0928^{* * *}$ & $0.1184^{* * *}$ & $0.1097^{* * *}$ & -0.0005 & -0.0036 \\
Win 1.0m or more Pre-HS Grad & $(0.0279)$ & $(0.0267)$ & $(0.0257)$ & $(0.0246)$ & $(0.0227)$ & $(0.0226)$ \\
\hline Child, Parent, and Family Controls & & $\mathrm{X}$ & & $\mathrm{X}$ & & $\mathrm{X}$ \\
State-by-Year and Cohort & $\mathrm{X}$ & $\mathrm{X}$ & $\mathrm{X}$ & $\mathrm{X}$ & $\mathrm{X}$ & $\mathrm{X}$ \\
\hline R-Squared & 0.015 & 0.142 & 0.018 & 0.104 & 0.021 & 0.049 \\
Mean Dep & 0.348 & 0.348 & 0.219 & 0.219 & 0.144 & 0.144 \\
Observations & $1,461,262$ & $1,461,262$ & $1,461,262$ & $1,461,262$ & $1,461,262$ & $1,461,262$ \\
\hline \hline
\end{tabular}

Note: Estimates show the percentage point effect of income shocks on attending any college, a four-year college, or a two-year college in the year of high school graduation. Students for whom the win occurs prior to high school graduation are potentially affected. Columns 1, 3, and 5 include state-by-year of win and cohort fixed effects. Columns 2, 4, and 6 add parent wages, adjusted gross income, filing status (joint or single), gender, citizenship, missing returns, mortgage payments, Social Security income, self-employment income, the number of children in the household, child gender, citizenship, and an indicator for Social Security birth match to parent. All student and parent controls are based on pre-win measures. Win sizes are classified according to six cutoffs: $\$ 10,000, \$ 30,000, \$ 100,000, \$ 300,000, \$ 1,000,000$, and exceeding $\$ 1,000,000$. Errors are clustered at the winner level. The symbols *,**, and $* * *$ represent statistical significance at 10,5 , and 1 percent respectively. 
Table 5: Four-Year College Attendance: Linear Estimates and Test For Concavity

\begin{tabular}{|c|c|c|c|}
\hline & & $\begin{array}{c}(1) \\
\text { Quadratic }\end{array}$ & $\begin{array}{c}(2) \\
\text { Linear }\end{array}$ \\
\hline \multirow[t]{2}{*}{ Range: 0 to 50 million } & Pre-HS Grad * Win Amt $(\$ 100 k)$ & $\begin{array}{l}0.003338^{* * *} \\
(0.000659)\end{array}$ & $\begin{array}{l}0.000743^{* *} \\
(0.000311)\end{array}$ \\
\hline & Pre-HS Grad * Win Amt $(\$ 100 k)^{2}$ & $\begin{array}{l}-0.0000100^{* * *} \\
(0.0000024)\end{array}$ & \\
\hline \multirow[t]{2}{*}{ Range: 0 to 25 million } & Pre-HS Grad * Win Amt $(\$ 100 k)$ & $\begin{array}{l}0.005205^{* * *} \\
(0.000938)\end{array}$ & $\begin{array}{l}0.001632^{\text {*** }} \\
(0.000446)\end{array}$ \\
\hline & Pre-HS Grad $*$ Win Amt $(\$ 100 k)^{2}$ & $\begin{array}{l}-0.000025^{\text {*** }} \\
(0.000006)\end{array}$ & \\
\hline \multirow[t]{2}{*}{ Range: 0 to 10 million } & Pre-HS Grad * Win Amt $(\$ 100 k)$ & $\begin{array}{l}0.007079^{* * *} \\
(0.001656)\end{array}$ & $\begin{array}{l}0.004082^{\text {*** }} \\
(0.000765)\end{array}$ \\
\hline & Pre-HS Grad * Win Amt $(\$ 100 k)^{2}$ & $\begin{array}{l}-0.000048^{*} \\
(0.000026)\end{array}$ & \\
\hline \multirow[t]{2}{*}{ Range: 0 to 5 million } & Pre-HS Grad * Win Amt $(\$ 100 k)$ & $\begin{array}{l}0.007133^{* * *} \\
(0.002384)\end{array}$ & $\begin{array}{l}0.005948^{* * *} \\
(0.001209)\end{array}$ \\
\hline & Pre-HS Grad * Win Amt $(\$ 100 \mathrm{k})^{2}$ & $\begin{array}{l}-0.000049 \\
(0.000082)\end{array}$ & \\
\hline \multirow[t]{2}{*}{ Range: 0 to 2.5 million } & Pre-HS Grad * Win Amt $(\$ 100 k)$ & $\begin{array}{l}0.006362^{*} \\
(0.003360)\end{array}$ & $\begin{array}{l}0.006655^{\text {*** }} \\
(0.001760)\end{array}$ \\
\hline & Pre-HS Grad * Win Amt $(\$ 100 k)^{2}$ & $\begin{array}{l}0.000026 \\
(0.000262)\end{array}$ & \\
\hline \multirow[t]{2}{*}{ Range: 0 to 1 million } & Pre-HS Grad $*$ Win Amt $(\$ 100 k)$ & $\begin{array}{l}0.005155 \\
(0.005178)\end{array}$ & $\begin{array}{l}0.008476^{\text {*** }} \\
(0.002590)\end{array}$ \\
\hline & Pre-HS Grad * Win Amt $(\$ 100 k)^{2}$ & $\begin{array}{l}0.000523 \\
(0.000879)\end{array}$ & \\
\hline \multirow[t]{2}{*}{ Range: 0 to $500 \mathrm{k}$} & Pre-HS Grad * Win Amt $(\$ 100 k)$ & $\begin{array}{l}0.002671 \\
(0.008221)\end{array}$ & $\begin{array}{l}0.006374^{*} \\
(0.003752)\end{array}$ \\
\hline & Pre-HS Grad $*$ Win Amt $(\$ 100 \mathrm{k})^{2}$ & $\begin{array}{l}0.001473 \\
0.003037)\end{array}$ & \\
\hline
\end{tabular}

Note: Estimates show the percentage point effect of income shocks on four-year college enrollment in the year of high school graduation. The linear specification interacts the win amount (in hundreds of thousands of dollars) with an indicator for the win occurring prior to high school graduation. A quadratic in win amount is used to test for concavity over various income shock ranges. Students for whom the win occurs prior to high school graduation are potentially affected. The specifications include state-by-year of win fixed effects, cohort fixed effects, parent wages, adjusted gross income, filing status (joint or single), gender, citizenship, missing returns, mortgage payments, Social Security income, self-employment income, the number of children in the household, and child gender, citizenship, and an indicator for Social Security birth match to parent. All student and parent controls are based on pre-win measures. Errors are clustered at the winner level. The symbols *, **, and *** represent statistical significance at 10,5 , and 1 percent respectively. 
Table 6: Four-Year College Attendance: Alternative Specifications of Key Variables

\begin{tabular}{llccll}
\hline \hline & \multicolumn{1}{c}{$(1)$} & \multicolumn{1}{c}{$(2)$} & $\begin{array}{c}(3) \\
\text { Enrollment } \\
\text { Within }\end{array}$ & \multicolumn{1}{c}{ (4) } & (5) \\
& $\begin{array}{c}\text { Pre-Tax } \\
\text { Income }\end{array}$ & $\begin{array}{c}\text { Post-Tax } \\
\text { Income }\end{array}$ & $\begin{array}{c}\text { Two Years } \\
\text { (Annual) }\end{array}$ & $\begin{array}{c}\text { Elasticity } \\
\text { (Lifetime) }\end{array}$ \\
\hline Win Amount $(\$ 100 \mathrm{k}) *$ Pre-HS Grad & $\begin{array}{l}0.0060^{* * *} \\
(0.0012)\end{array}$ & $\begin{array}{l}0.0089^{* * *} \\
(0.0018)\end{array}$ & $\begin{array}{l}0.0073^{* * *} \\
(0.0013)\end{array}$ & $\begin{array}{l}0.0122^{* * *} \\
(0.0025)\end{array}$ & $\begin{array}{l}0.2195^{* * *} \\
(0.0446)\end{array}$ \\
\hline Mean Dep & 0.219 & 0.219 & 0.270 & 0.219 & 0.219 \\
Observations & $1,460,890$ & $1,460,890$ & $1,460,890$ & $1,460,890$ & $1,460,890$ \\
\hline \hline
\end{tabular}

Note: This table presents estimates of the effect of income shocks on four-year college attendance when accounting for taxes, when expanding the definition of enrollment to include the year after the expected high school graduation year, and as the elasticity of attendance with respect to household income. Estimates in columns 1 and 2 are the percentage point effect of income shocks on college attendance before and after taxes are deducted from lottery winnings, respectively. Taxes are estimated based on household income in the year prior to the lottery win. Column 3 presents estimates based on attendance in the year of expected high school graduation or in the subsequent year. The linear specifications in columns 1, 2, and 3 interact the win amount (in hundreds of thousands of dollars) with an indicator for the win occurring prior to high school graduation. Columns 4 and 5 present the elasticity of attendance with respect to estimated average annual household income and total household income earned when the child is aged 1 to 18, respectively. Attention in each column is restricted to lottery wins of 5 million dollars or less. The specifications include state-by-year of win fixed effects and cohort fixed effects. Errors are clustered at the winner level. The symbols $* * *$, and $* * *$ represent statistical significance at 10, 5, and 1 percent respectively. See Appendix Table A9 for the full set of interaction terms and main effects for each specification. 
Table 7: Four-Year College Attendance in Later Years and Cumulatively

\begin{tabular}{|c|c|c|c|c|c|c|}
\hline & $\begin{array}{c}(1) \\
\text { Year } 0\end{array}$ & $\begin{array}{c}(2) \\
\text { Year } 1\end{array}$ & $\begin{array}{c}(3) \\
\text { Year } 2\end{array}$ & $\begin{array}{c}(4) \\
\text { Year } 3\end{array}$ & $\begin{array}{c}5) \\
\text { Year } 4\end{array}$ & $\begin{array}{c}(6) \\
\text { Total }\end{array}$ \\
\hline Win $10-30 k$ Pre-HS Grad & $\begin{array}{l}-0.0016 \\
(0.0035)\end{array}$ & $\begin{array}{l}-0.0036 \\
(0.0037)\end{array}$ & $\begin{array}{l}-0.0015 \\
(0.0039)\end{array}$ & $\begin{array}{l}-0.0025 \\
(0.0043)\end{array}$ & $\begin{array}{l}-0.0027 \\
(0.0047)\end{array}$ & $\begin{array}{l}-0.0331 \\
(0.0208)\end{array}$ \\
\hline Win $30-100 k$ Pre-HS Grad & $\begin{array}{l}-0.0075 \\
(0.0062)\end{array}$ & $\begin{array}{l}0.0002 \\
(0.0064)\end{array}$ & $\begin{array}{l}0.0011 \\
(0.0068)\end{array}$ & $\begin{array}{l}0.0029 \\
(0.0075)\end{array}$ & $\begin{array}{l}0.0011 \\
(0.0083)\end{array}$ & $\begin{array}{l}0.0072 \\
(0.0365)\end{array}$ \\
\hline Win 100-300k Pre-HS Grad & $\begin{array}{l}0.0188^{* *} \\
(0.0091)\end{array}$ & $\begin{array}{l}0.0244^{* * *} \\
(0.0094)\end{array}$ & $\begin{array}{l}0.0259^{* * *} \\
(0.0099)\end{array}$ & $\begin{array}{l}0.0225^{* *} \\
(0.0108)\end{array}$ & $\begin{array}{l}0.0255^{* *} \\
(0.0119)\end{array}$ & $\begin{array}{l}0.1249^{* *} \\
(0.0527)\end{array}$ \\
\hline Win 300k-1.0m Pre-HS Grad & $\begin{array}{l}0.0539^{* * *} \\
(0.0195)\end{array}$ & $\begin{array}{l}0.0343^{*} \\
(0.0194)\end{array}$ & $\begin{array}{l}0.0309 \\
(0.0206)\end{array}$ & $\begin{array}{l}0.0444^{* *} \\
(0.0227)\end{array}$ & $\begin{array}{l}0.0397 \\
(0.0250)\end{array}$ & $\begin{array}{l}0.2583^{* *} \\
(0.1091)\end{array}$ \\
\hline Win $1.0 \mathrm{~m}$ or more Pre-HS Grad & $\begin{array}{l}0.1184^{* * *} \\
(0.0257)\end{array}$ & $\begin{array}{l}0.1221^{* * *} \\
(0.0272)\end{array}$ & $\begin{array}{l}0.1371^{\text {*** }} \\
(0.0294)\end{array}$ & $\begin{array}{l}0.1451^{\text {*** }} \\
(0.0316)\end{array}$ & $\begin{array}{l}0.0956^{* * *} \\
(0.0353)\end{array}$ & $\begin{array}{l}0.6070^{* * *} \\
(0.1545)\end{array}$ \\
\hline Mean Dep & 0.215 & 0.242 & 0.238 & 0.238 & 0.219 & 1.162 \\
\hline Observations & $1,461,262$ & $1,461,262$ & $1,292,594$ & $1,060,514$ & 840,030 & 840,030 \\
\hline
\end{tabular}

Note: Estimates show the percentage point effect of income shocks on four-year college enrollment in the years after high school graduation and the cumulative number of years of enrollment during this period. Year 0 refers to the calendar year in which a student is expected to graduate from high school based on his or her state and date of birth (baseline specification). Years 1 to 4 correspond to the subsequent calendar years. Students for whom the win occurs prior to high school graduation are potentially affected. Students who could endogenously change their enrollment decision are excluded in each column (e.g. the children of parents who won in Year 1 and Year 2 are excluded when estimating the change in enrollment in Year 3). The specifications include state-by-year of win fixed effects and cohort fixed effects. Win sizes are classified according to six cutoffs: $\$ 10,000, \$ 30,000, \$ 100,000, \$ 300,000, \$ 1,000,000$, and exceeding $\$ 1,000,000$. Errors are clustered at the winner level. The symbols $* * *$, and $* * *$ represent statistical significance at 10,5 , and 1 percent respectively. 
Table 8: Four-Year College Attendance: Heterogeneity by Financial Constraints

\begin{tabular}{|c|c|c|c|c|c|c|c|}
\hline Household tax records & $\begin{array}{c}\text { (1) } \\
\text { Income }\end{array}$ & $\begin{array}{c}(2) \\
\text { Investment } \\
\text { Income } \\
\end{array}$ & $\begin{array}{c}\text { (3) } \\
\text { Retirement } \\
\text { Contribution }\end{array}$ & Mortgage & $\begin{array}{c}\text { (5) } \\
\text { Imputed } \\
\text { Wealth }\end{array}$ & $\begin{array}{c}\text { (6) } \\
\text { Pell } \\
\text { Eligible }\end{array}$ & $\begin{array}{c}\text { (7) } \\
\text { Imputed } \\
\text { EFC }\end{array}$ \\
\hline $\begin{array}{l}\text { Win Amt (\$100k) Pre-HS Grad } \\
* \text { Less Constrained }\end{array}$ & $\begin{array}{l}0.0065^{* * *} \\
(0.0024)\end{array}$ & $\begin{array}{l}0.0049^{*} \\
(0.0025)\end{array}$ & $\begin{array}{l}0.0044^{*} \\
(0.0026)\end{array}$ & $\begin{array}{l}0.0035 \\
(0.0026)\end{array}$ & $\begin{array}{l}0.0070^{* * *} \\
(0.0025)\end{array}$ & $\begin{array}{l}0.0051^{* *} \\
(0.0024)\end{array}$ & $\begin{array}{l}0.0048^{* *} \\
(0.0024)\end{array}$ \\
\hline SCF imputations & $\begin{array}{c}(8) \\
\text { Denied } \\
\text { Credit } \\
\end{array}$ & $\begin{array}{c}\text { (9) } \\
\text { Late } \\
\text { Payment } \\
\end{array}$ & $\begin{array}{c}(10) \\
\text { Payment } \\
\text {-to-Income } \\
\text { Ratio } \\
\end{array}$ & $\begin{array}{c}\text { (11) } \\
\text { Debt-to- } \\
\text { Asset } \\
\text { Ratio } \\
\end{array}$ & $\begin{array}{l}\text { Liquid } \\
\text { Assets }\end{array}$ & $\begin{array}{c}(13) \\
\text { Liquid } \\
\text { Assets }+ \\
\text { Home Equity } \\
\end{array}$ & $\begin{array}{c}\text { Net } \\
\text { Worth }\end{array}$ \\
\hline $\begin{array}{l}\text { Win Amt (\$100k) Pre-HS Grad } \\
* \text { Less Constrained }\end{array}$ & $\begin{array}{l}0.0092^{* * *} \\
(0.0023)\end{array}$ & $\begin{array}{l}0.0082^{* * *} \\
(0.0023)\end{array}$ & $\begin{array}{l}0.0027 \\
(0.0026)\end{array}$ & $\begin{array}{l}0.0045^{*} \\
(0.0026)\end{array}$ & $\begin{array}{l}0.0077^{* * *} \\
(0.0025)\end{array}$ & $\begin{array}{l}0.0087^{* * *} \\
(0.0025)\end{array}$ & $\begin{array}{l}0.0078^{* * *} \\
(0.0025)\end{array}$ \\
\hline Economic environment & $\begin{array}{c}\text { (15) } \\
\text { County } \\
\text { Poverty } \\
\text { Rate }\end{array}$ & $\begin{array}{c}\text { (16) } \\
\text { County } \\
\text { Food } \\
\text { Stamp Rate }\end{array}$ & $\begin{array}{c}\text { (17) } \\
\text { County } \\
\text { Insured } \\
\text { Rate } \\
\end{array}$ & $\begin{array}{c}(18) \\
\text { County } \\
\text { Medicaid } \\
\text { Rate } \\
\end{array}$ & $\begin{array}{c}(19) \\
\text { Zip } \\
\text { House } \\
\text { Values } \\
\end{array}$ & $\begin{array}{c}(20) \\
\text { Zip House } \\
\text { Values } \\
\text { (w/ House) }\end{array}$ & $\begin{array}{c}(21) \\
\text { Great } \\
\text { Recession } \\
\text { Years } \\
\end{array}$ \\
\hline \multirow[t]{2}{*}{$\begin{array}{l}\text { Win Amt (\$100k) Pre-HS Grad } \\
* \text { Less Constrained }\end{array}$} & $\begin{array}{l}0.0042 \\
(0.0027) \\
\end{array}$ & $\begin{array}{l}0.0000 \\
(0.0028)\end{array}$ & $\begin{array}{l}0.0065 * * * \\
(0.0024) \\
\end{array}$ & $\begin{array}{l}-0.0006 \\
(0.0025)\end{array}$ & $\begin{array}{l}-0.0029 \\
(0.0027)\end{array}$ & $\begin{array}{l}0.0015 \\
(0.0036)\end{array}$ & $\begin{array}{l}0.0005 \\
(0.0028) \\
\end{array}$ \\
\hline & Mean & $\mathrm{ep}=0.219$ & Observ & $\mathrm{s}=1,46$ & & & \\
\hline
\end{tabular}

Note: Estimates show the differential effect of income shocks on attending a four-year college for households that are less financially constrained relative to those that are more constrained. The estimates are based on a linear specification that interacts the pre-tax win amount (in hundreds of thousands of dollars) with an indicator for the win occurring prior to high school graduation and a measure of household financial constraints. Estimates in the top panel are differentiated based on pre-win characteristics available in the tax records or estimated by applying the FAFSA formula to tax data. Less constrained households are those with above median income, any investment income, any voluntary retirement contributions, a mortgage, above median wealth, Pell Grant ineligible, or above median expected household contribution (EFC). The second panel differentiates the estimates by measures of financial constraints imputed using the Survey of Consumer Finances. Less constrained households are those that have below median probability of being denied credit, probability of making late payments, monthly payment-todebt ratio, debt-to-asset ratio, or have above median liquid assets, liquid assets and home equity, or total net worth. In the bottom panel, less constrained households are those that live in counties with below median poverty, food stamp, and Medicaid rates, above median health insurance coverage rates, that live in zip codes with above median housing values, or who have children who graduate before or after the Great Recession years of 2008 to 2012. Attention is restricted to lottery wins of 5 million dollars or less. The specifications include state-by-year of win fixed effects and cohort fixed effects. Errors are clustered at the winner level. The symbols *,**, and *** represent statistical significance at 10, 5, and 1 percent respectively. See Appendix Table A22 for the sub-interaction term for each specification. 
Table 9: Four-Year College Attendance: Heterogeneity by Timing

\begin{tabular}{|c|c|c|c|c|}
\hline & \multirow{2}{*}{\multicolumn{2}{|c|}{$\begin{array}{l}(1) \\
\text { Average Trends }\end{array}$}} & \multirow{2}{*}{\multicolumn{2}{|c|}{$\begin{array}{l}\text { (3) } \\
\text { Trends by Income }\end{array}$}} \\
\hline & & & & \\
\hline & 6 Years & All Years & 6 Years & All Years \\
\hline Above Med Inc * Yrs Pre Grad * Win Amt (\$100k) Pre-HS Grad & & & $\begin{array}{l}-0.0008 \\
(0.0014)\end{array}$ & $\begin{array}{l}-0.0010 \\
(0.0009)\end{array}$ \\
\hline Yrs Pre Grad * Win Amt (\$100k) Pre-HS Grad & $\begin{array}{l}0.0001 \\
(0.0007)\end{array}$ & $\begin{array}{l}-0.0001 \\
(0.0005)\end{array}$ & $\begin{array}{l}0.0012 \\
(0.0010)\end{array}$ & $\begin{array}{l}0.0007 \\
(0.0007)\end{array}$ \\
\hline Mean Dep & 0.219 & 0.224 & 0.219 & 0.224 \\
\hline Observations & $1,460,890$ & $1,902,983$ & $1,460,890$ & $1,902,983$ \\
\hline
\end{tabular}

Note: This table presents a test of whether the effect of a lottery win varies with the timing of the win relative to a child's high school graduation. The number of years between the win and the year of high school graduation is interacted with the win amount (in hundreds of thousands of dollars). Estimates are presented for wins that occur in the six years prior to graduation and for all lottery wins, extending as far back as 14 years prior to graduation. Columns 3 and 4 differentiate the effects for households with above and below median income $(\$ 44,699)$. Attention is restricted to lottery wins of 5 million dollars or less. The specifications include state-by-year of win fixed effects and cohort fixed effects. Errors are clustered at the winner level. The symbols *,**, and $* * *$ represent statistical significance at 10, 5, and 1 percent respectively. See Appendix Table A31 for the full set of interaction terms and main effects for each specification. 
Table 10: College Attendance and Federal Aid: Critical FAFSA Year

\begin{tabular}{|c|c|c|c|c|}
\hline \multirow[b]{3}{*}{ All Households } & \multicolumn{2}{|c|}{$\begin{array}{ll}(1) & (2)\end{array}$} & \multicolumn{2}{|l|}{ (3) } \\
\hline & \multicolumn{2}{|c|}{ Non-FAFSA Year } & \multicolumn{2}{|c|}{ FAFSA Year } \\
\hline & Attend 4-Yr & Pell Grants & Attend 4-Yr & Pell Grants \\
\hline Win $10-30 k$ Pre-HS Grad & $\begin{array}{l}-0.0020 \\
(0.0038)\end{array}$ & $\begin{array}{l}-53.47 \\
(40.56)\end{array}$ & $\begin{array}{l}0.0002 \\
(0.0058)\end{array}$ & $\begin{array}{l}-461.95^{\text {*** }} \\
(55.23)\end{array}$ \\
\hline Win 30-100k Pre-HS Grad & $\begin{array}{l}-0.0055 \\
(0.0067)\end{array}$ & $\begin{array}{l}-103.08 \\
(71.17)\end{array}$ & $\begin{array}{l}-0.0149 \\
(0.0102)\end{array}$ & $\begin{array}{l}-817.47^{* * *} \\
(91.43)\end{array}$ \\
\hline Win 100-300k Pre-HS Grad & $\begin{array}{l}0.0193^{*} \\
(0.0099)\end{array}$ & $\begin{array}{l}-108.10 \\
(93.86)\end{array}$ & $\begin{array}{l}0.0158 \\
(0.0149)\end{array}$ & $\begin{array}{l}-556.27^{* * *} \\
(121.91)\end{array}$ \\
\hline Win 300k-1.0m Pre-HS Grad & $\begin{array}{l}0.0521^{* *} \\
(0.0211)\end{array}$ & $\begin{array}{l}261.11 \\
(200.69)\end{array}$ & $\begin{array}{l}0.0594^{*} \\
(0.0339)\end{array}$ & $\begin{array}{l}-613.61^{* *} \\
(252.73)\end{array}$ \\
\hline Win $1.0 \mathrm{~m}$ or more Pre-HS Grad & $\begin{array}{l}0.1057^{* * *} \\
(0.0273)\end{array}$ & $\begin{array}{l}-514.94^{* *} \\
(258.46)\end{array}$ & $\begin{array}{l}0.1673^{* * *} \\
(0.0489)\end{array}$ & $\begin{array}{l}-1,295.88^{* * *} \\
(240.61)\end{array}$ \\
\hline Mean Dep & 0.219 & $1,577.16$ & 0.219 & $1,577.16$ \\
\hline \multirow[t]{3}{*}{ Observations } & $1,317,523$ & $1,317,523$ & 961,290 & 961,290 \\
\hline & & $(6)$ & $(7)$ & $(8)$ \\
\hline & \multicolumn{2}{|c|}{ Non-FAFSA Year } & \multicolumn{2}{|c|}{ FAFSA Year } \\
\hline Below Median Income Households & Attend 4-Yr & Pell Grants & Attend 4-Yr & Pell Grants \\
\hline Win 10-30k Pre-HS Grad & $\begin{array}{l}0.0048 \\
(0.0046)\end{array}$ & $\begin{array}{l}-54.18 \\
(102.62)\end{array}$ & $\begin{array}{l}-0.0030 \\
(0.0070)\end{array}$ & $\begin{array}{l}-965.16^{* * *} \\
(144.42)\end{array}$ \\
\hline Win 30-100k Pre-HS Grad & $\begin{array}{l}-0.0098 \\
(0.0082)\end{array}$ & $\begin{array}{l}-259.90 \\
(183.33)\end{array}$ & $\begin{array}{l}-0.0044 \\
(0.0129)\end{array}$ & $\begin{array}{l}-1,791.89^{* * *} \\
(239.59)\end{array}$ \\
\hline Win 100-300k Pre-HS Grad & $\begin{array}{l}-0.0127 \\
(0.0126)\end{array}$ & $\begin{array}{l}-129.53 \\
(270.01)\end{array}$ & $\begin{array}{l}-0.0057 \\
(0.0197)\end{array}$ & $\begin{array}{l}-1,353.28^{\text {*** }} \\
(351.55)\end{array}$ \\
\hline Win 300k-1.0m Pre-HS Grad & $\begin{array}{l}0.0199 \\
(0.0272)\end{array}$ & $\begin{array}{l}401.76 \\
(563.83)\end{array}$ & $\begin{array}{l}0.0568 \\
(0.0445)\end{array}$ & $\begin{array}{l}-1,505.48^{* *} \\
(743.53)\end{array}$ \\
\hline Win $1.0 \mathrm{~m}$ or more Pre-HS Grad & $\begin{array}{l}0.0355 \\
(0.0402)\end{array}$ & $\begin{array}{l}-1,593.27^{* *} \\
(811.50)\end{array}$ & $\begin{array}{l}0.0464 \\
(0.0748)\end{array}$ & $\begin{array}{l}-2,841.31^{\text {*** }} \\
(947.44)\end{array}$ \\
\hline Mean Dep & 0.138 & $3,531.71$ & 0.138 & $3,531.71$ \\
\hline Observations & 657,385 & 657,385 & 469,214 & 469,214 \\
\hline
\end{tabular}

Note: Estimates show changes in the rate of four-year college attendance and receiving federal grants for all households in the top panel and households with below median income $(\$ 44,699)$ in the bottom panel. The first two columns exclude lottery wins in the critical FAFSA year (the year prior to high school graduation) and the next two columns only include the critical FAFSA year and post-graduation control years. Pell Grants are scaled by baseline attendance to reflect per-student changes. The specifications include state-by-year of win fixed effects and cohort fixed effects. Win sizes are classified according to six cutoffs: $\$ 10,000, \$ 30,000, \$ 100,000, \$ 300,000, \$ 1,000,000$, and exceeding $\$ 1,000,000$. Errors are clustered at the winner level. The symbols $* * *$, and $* * *$ represent statistical significance at 10,5 , and 1 percent respectively. 


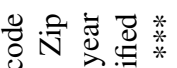

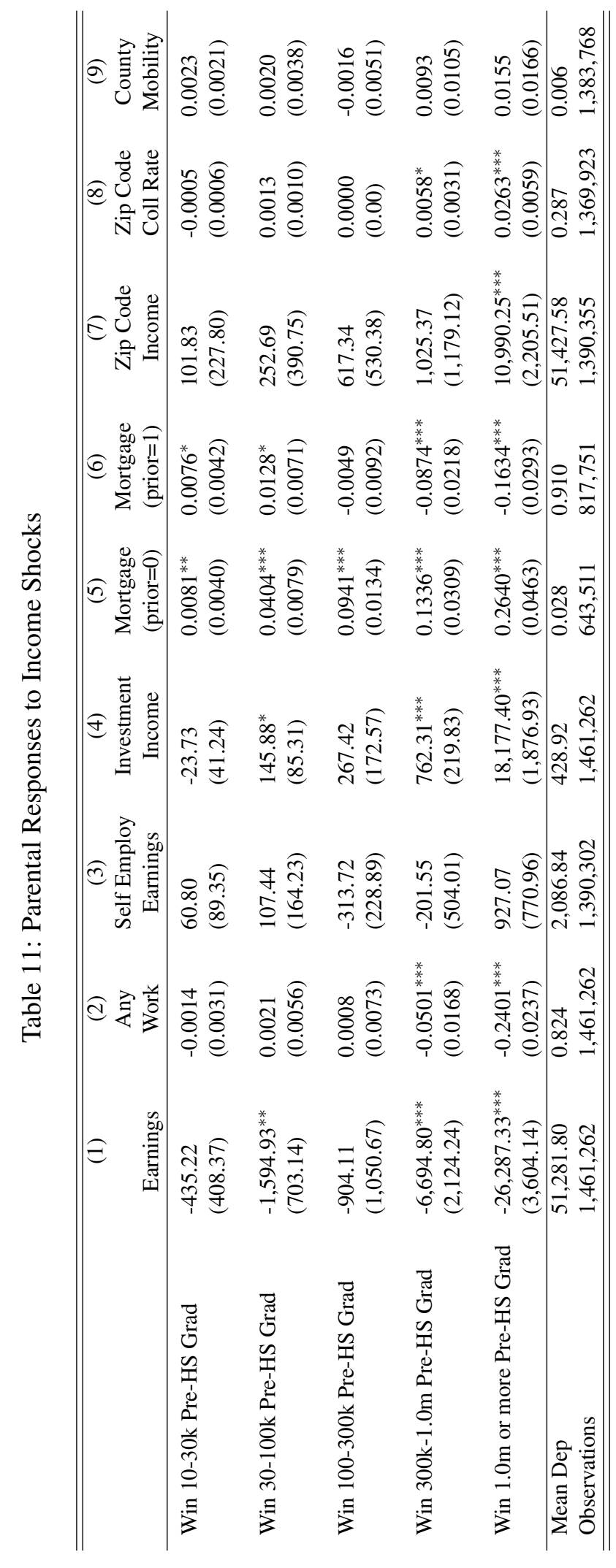

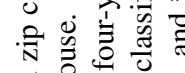

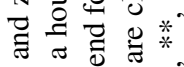

空

空

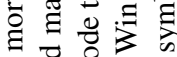

कo क्षे

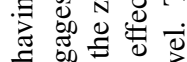

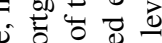

它

综 항

政

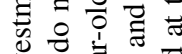

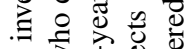

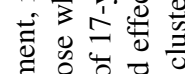

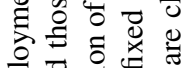

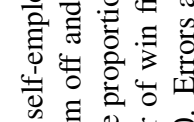

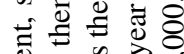

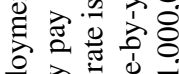

을 궁

है 해 की

诘

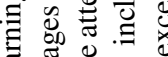

屯.

bo 항

웜

$\exists=0$

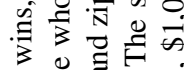

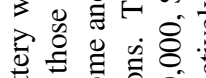

응 可.

$\circ$ 羟

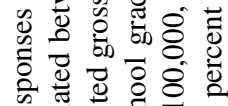

क्ष

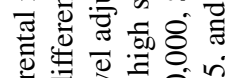

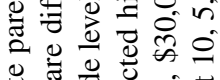

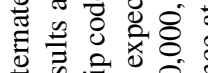

은 원.

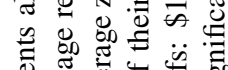

聯

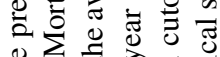

남

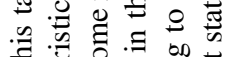

F

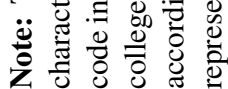


Table 12: Earnings and Savings: Heterogeneity Tests of Implied Marginal Propensity to Consume

\begin{tabular}{|c|c|c|c|c|}
\hline & 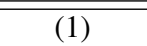 & 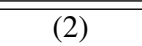 & (3) & 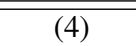 \\
\hline & \multicolumn{2}{|c|}{ Earnings } & \multicolumn{2}{|c|}{ Investment Income } \\
\hline Above Med Inc * Win Amt (\$100k) Pre-HS Grad & $\begin{array}{l}-606.10^{* *} \\
(237.27)\end{array}$ & $\begin{array}{l}-470.07^{* *} \\
(221.61)\end{array}$ & $\begin{array}{l}157.15^{*} \\
(81.48)\end{array}$ & $\begin{array}{l}166.82^{* *} \\
(67.37)\end{array}$ \\
\hline Home Owner * Win Amt (\$100k) Pre-HS Grad & & $\begin{array}{l}-303.34 \\
(228.49)\end{array}$ & & $\begin{array}{l}-24.35 \\
(71.13)\end{array}$ \\
\hline Mean Dep & $51,275.28$ & $51,275.28$ & 428.51 & 428.51 \\
\hline Observations & $1,460,890$ & $1,460,890$ & $1,460,890$ & $1,460,890$ \\
\hline
\end{tabular}

Note: This table presents tests of whether the effects of lottery wins on earnings and investments vary with household income. An indicator for a household having above median income $(\$ 44,699)$ is interacted with the win amount (in hundreds of thousands of dollars). Results are presented with and without including an interaction for home ownership. The specifications include state-by-year of win fixed effects and cohort fixed effects. Attention is restricted to lottery wins of 5 million dollars or less. Errors are clustered at the winner level. The symbols *,**, and *** represent statistical significance at 10, 5, and 1 percent respectively. See Appendix Table A37 for the full set of interaction terms and main effects for each specification. 